\title{
Effect of elevated temperature on pull-out behaviour of 4DH/5DH hooked end steel fibres
}

\author{
Sadoon Abdallah, Mizi Fan* and David W.A. Rees \\ College of Engineering, Design and Physical Sciences, Brunel University London \\ Uxbridge, UB8 3PH, London, United Kingdom
}

\section{Abstract}

This paper presents the effect of elevated temperature on the bond mechanisms associated with the pull-out behaviour of steel fibres. A series of pull-out tests have been performed on 4D and 5D hooked end steel fibres embedded in four different types of concrete, namely, normal strength concrete (NSC), medium strength concrete (MSC), high strength concrete (HSC) and ultra-high performance mortar (UHPM). At the age of 90 days, the specimens were heated to target temperatures of $100,200,300,400,500,600,700$ and $800^{\circ} \mathrm{C}$ respectively. The influence of elevated temperature on the mechanical and thermal properties of concrete was investigated. The results showed that the pull-out response of both fibres does not vary significantly throughout $20-400^{\circ} \mathrm{C}$ temperature range, but within the temperature range of 600 to $800^{\circ} \mathrm{C}$, the pull-out strength decreases significantly for all concretes. The comparisons between the two fibre types show that the mechanical anchorage contribution provided by the $5 \mathrm{DH}$ fibre is significantly higher than that of the 4DH fibre, especially for higher strength concretes. The reduction in bond strength of both fibres after elevated temperature exposure is found to correlate closely with the degradation in compressive strength of the concretes.

\section{Keywords:}

Pull-out behaviour Bonding mechanism

Elevated temperature Hooked end fibres

Mechanical anchorage

*Corresponding author: Professor, Head of Civil Engineering Department and Research Director, Brunel University London, Email: mizi.fan@brunel.ac.uk,Tel.: +44 1895266466 


\section{Introduction}

Concrete structures are inevitably exposed to potential risks, such as earthquakes, explosion and fire during their service lives. Fire represents one of the major hazards for high-rise buildings, tunnels and other infrastructures [1,2]. Fire safety measures are one of the main considerations in the design of structural members and complex infrastructures, such as tunnels, where concrete is widely used as a primary construction material [3].

It is well established that the addition of randomly distributed steel fibres to a cementitious matrix could improve significantly its tensile behaviour, ductility, impact and crack resistances [4-7]. Although steel fibres may not offer any obvious advantage from a fireendurance point of view, it has been shown that steel fibres can be considered as an effective way in delaying the spread of cracking, and hence potentially improve the performance of concrete after exposure to high temperatures [8-10]. The main concern about the structural performance is the condition of the constituent materials (i.e. steel fibre and concrete) and the bond characteristics between them. At high temperatures, the mechanical and physical properties of the concrete and reinforcing steel fibres, as well as the bond characteristics between these materials, may deteriorate significantly [11].

The strength of steel fibre reinforced concrete (SFRC) under different levels of elevated temperature can be quite variable, depending mainly on the fibre-matrix bond strength. Therefore, understanding the bond characteristics between steel fibres and concrete after exposure to high temperatures is paramount when quantifying SFRC behaviour, especially for the most widely used hooked end fibres. The bond characteristics are commonly assessed using the single fibre pull-out test, which provides the interfacial properties between the fibres and the surrounding cementitious matrix [12]. 
57 While the bond between steel fibre and matrix at room temperature has been a popular topic for many years [e.g. 13-16], information on the bond characteristics after exposure to elevated temperatures is very limited. In this context, a series of experimental pull-out tests on two types of widely used hooked end steel fibres, namely 4D and 5D fibres were performed in combination with four groups of cementitious mixtures with an initial compressive strength ranging between 33 and $148 \mathrm{MPa}$. The main objective of the research programme is to investigate the bond-slip mechanisms of these fibres, and how they are affected by exposure to prior elevated temperatures. The results are essential to a better understanding of the effects of elevated temperature on the bond characteristics, thereby allowing the post fire-resistance of SFRC to be predicted.

\section{Experimental program}

\subsection{Materials}

Four different concrete grades were investigated, namely normal strength concrete (NSC), medium strength concrete (MSC), high strength concrete (HSC) and ultra-high performance mortar (UHPM). All were prepared using two classes of Ordinary Portland Cement (i.e. CEM II 32.5R and CEM III 52.5N) according to European standard EN 197-1[17]. Silica fume, ground quartz and fly ash were also used for the preparation of the MSC, HSC and UHPM mixtures. The aggregates consisted of crushed granite with a maximum size of $10 \mathrm{~mm}$. Two types of sand were used. Coarse sand (0-4 mm) was used in the NSC, MSC and HSC mix design and very fine sand $(150-600 \mu \mathrm{m})$ was used in the UHPM mix design. A superplasticizer TamCem23SSR was used to enhance the workability of the HSC and UHPM mixtures. The mix proportions are given in Table 1.

Two types of commercially available Dramix hooked end steel fibres, namely 4DH and 5DH were used in the pull-out tests. These fibres have the same length $(60 \mathrm{~mm})$, diameter $(0.9$ 
$\mathrm{mm})$ and aspect ratio $(l / d=65)$, but only differ in the hook geometry and tensile strength. The geometrical properties of hooked end fibres are depicted in Fig. 1 and detailed in Table 2. The ambient stress-strain curves obtained for the fibre tensile tests are shown in Fig. 2.

\subsection{Sample preparation}

The pull-out test specimens prepared were $(100 \times 100 \times 100 \mathrm{~mm})$ cubes for NSC, MSC and HSC and $100 \times 50 \mathrm{~mm}$ cylinders with a diameter of $100 \mathrm{~mm}$ and a height of $50 \mathrm{~mm}$ for the UHPM specimens. For NSC, MSC and HSC specimens, each specimen consists of four embedded fibres, while the UHPM specimens contained one embedded fibre. The fibre embedment length was $30 \mathrm{~mm}$, which is half the length of the fibre used in this investigation. For each concrete mix, three additional $100 \mathrm{~mm}$ cubes were prepared in order to determine the compressive strength and mass loss of the mixture. Immediately after casting and vibration, the specimens were covered with a thin polyethylene film in order to minimise moisture loss and left for 24 hours at room temperature. The specimens were demoulded after 24 hours and then cured for a further 28 days in the conditioning chamber, which was controlled to have a temperature of $20 \pm 2^{\circ} \mathrm{C}$ and relative humidity of $95 \pm 5 \%$. Thereafter each test specimens was aged for 90 days before testing.

\subsection{Heating scheme}

At the age of 90 days, the pull-out and compressive strength specimens were placed in an electrical high-temperature furnace. For the pull-out specimens, the free end of the steel fibre was coated with intumescent coating for protection during the heating. The specimens were then heated to a maximum target temperature of $100,200,300,400,500,600,700$ and $800^{\circ} \mathrm{C}$, at a heating rate of $20^{\circ} \mathrm{C} / \mathrm{min}$. The target temperatures were maintained for one hour 
following which the specimens were allowed to cool down naturally before being tested at room temperature.

\subsection{Test setup}

107 The pull-out tests were performed on the cooled specimens using a specially designed grip system, as illustrated in Fig. 3, which was attached to an Instron 5584 universal testing machine. The grips were designed such that the forces applied to the fibre provided a true

110 reflection of the real situation experienced by fibres bridging a crack. The body of the gripping system was machined in a lathe using mild steel and had a tapered end to allow the insertion of four M4 grub screws (Fig. 3). These were then tightened around the steel fibre to an equal torque to ensure an even distribution of gripping pressure and to minimise deformation or breakage of the fibre ends. Two linear variable differential transformer (LVDT) transducers were used to measure the distance travelled by the steel fibre relative to the concrete face during testing (i.e. the pull-out distance). They were held in place using aluminium sleeves on either side of the main grip body (Fig. 3). The LVDT's had ball bearings at the tips to allow for accurate readings on the face of the samples. The sample was secured to the Instron base using clamps with riser blocks and M16 studs. The specimen was positioned on a brass round disc to remove any discrepancies in the sample base and allow

121 for distortion. In all pull-out tests, a displacement rate of $10 \mu \mathrm{m} / \mathrm{s}$ was adopted. All specimens were tested at an age of $90 \pm 2$ days and the average value of three specimens was adopted, both for the compressive strength and pull-out tests. 


\section{Results and discussion}

\subsection{Mechanical and thermal properties of cementitious mixes at elevated temperatures}

126

127

\subsubsection{Compressive strength}

It is well known that the compressive strength is usually used to determine the grade of the concrete strength from which the mechanical properties of the concrete can be assessed. The compressive strength of all mixes after exposure to various levels of elevated temperature are summarized in Table 3 and shown in Fig. 4. Note that results are presented only for the UHPM mix up to $400^{\circ} \mathrm{C}$ because explosive spalling occurred at higher temperatures (Fig. 5). For NSC, MSC and HSC, no an explosive spalling occurred at any temperature except spalling of small fragments from top surface of the specimens (Fig. 5). It can be seen from Fig. 4 that after an exposure to relatively low levels of elevated temperature $\left(<400^{\circ} \mathrm{C}\right)$, increasing temperature results in a slight decrease in the compressive strength of NSC, MSC and $\mathrm{HSC}$, with an exceptional result at $200^{\circ} \mathrm{C}$, showing a slight increase in compressive strength owing to rehydration and moisture migration. By contrast, for the UHPM mix, the compressive strength increased slightly following exposure to temperatures within the 100$300^{\circ} \mathrm{C}$ range before dropping at $400^{\circ} \mathrm{C}$.

Further exposure to $400-800^{\circ} \mathrm{C}$ results in consistent decrease in the compressive strength of NSC, MSC and HSC with the temperature increases. At $800^{\circ} \mathrm{C}$, the compressive strength retention of NSC, MSC and HSC were $33 \%, 42 \%$ and $47 \%$ of original values at ambient temperature, respectively. The significant reduction in strength may be attributed to both the physical and chemical transformation that takes place in concrete, resulting in decomposition of calcium silicate hydrate (C-S-H) gel which leads to loss of binder property in concrete. 
147 Fig. 6 illustrates the mass loss as a percentage of the original ambient value $\left(\mathrm{M}_{\mathrm{loss}}\right)$ for all concrete mixtures after exposure to different levels of elevated temperature. The mass of each specimen was measured before heating and again after cooling in order to determine the mass loss ratio. As evident from the figure, for all mixtures the mass loss remained insignificant $(<3 \%)$ until about $300^{\circ} \mathrm{C}$, and then the loss increased substantially when temperatures change from 300 t0 $800^{\circ} \mathrm{C}$. When temperature reached $800^{\circ} \mathrm{C}$, the mass losses of NSC, MSC and HSC were $11 \%, 10 \%$, and $8 \%$, respectively. It can be concluded that the compressive strength of concrete does not have a significant influence on mass loss, e.g. HSC exhibits a similar trend in mass loss to that of NSC.

\subsection{Post-heating pull-out behaviour}

\subsubsection{Pull-out load-slip response of $4 D H$ fibres.}

The average pull-out load-slip curves of 4DH fibre embedded in NSC, MSC, HSC and UHPM matrixes after exposure to different levels of elevated temperature $\left(20-800^{\circ} \mathrm{C}\right)$ are presented in Fig. 7. It can be seen that the pull-out behaviour of 4DH fibre embedded in all four matrixes is generally characterized by a combination of two different mechanisms: debonding and frictional pull-out. Once complete debonding has occurred at the fibre-matrix interface, the fibre hook undergoes plastic deformation to straighten the fibre. So, once these mechanisms are overcome, the pull-out process occurs under frictional resistance.

It can also be observed from Fig. 7a-d that the pull-out behaviour of the 4DH fibre embedded in each mixture is similar, especially for the lower temperature range (i.e. $20-400^{\circ} \mathrm{C}$ ).

167 However, there are some differences in the maximum pull-out load and pull-out work values. In this temperature range, the maximum pull-out load of $4 \mathrm{DH}$ fibre from the UHPM is $54 \%$, $35 \%$ and $15 \%$ higher than that of the fibre pulled from the NSC, MSC and HSC, respectively 
(Table 4). Another significant difference is that the residual pull-out load of the fibre pulled from the NSC (Fig. 7a) is greater than those from other matrixes. This higher residual response can be attributed to the fibre being pulled out without the occurrence of full deformation and straightening of the hook. Also from Fig. $7 \mathrm{~d}$ it is interesting to observe that some of the curves exhibit abrupt load drop corresponding to a partial rupture of the fibre's hook portion. Nevertheless, as illustrated in this figure, the broken fibre continued to withstand the stress transfer until the fibre completely pulled out; the hook at the other end of the fibre remained intact. In the higher temperature range between $500^{\circ} \mathrm{C}$ and $800^{\circ} \mathrm{C}$, there is a significant change in the shape of the pull-out curves with increasing pre-temperature, especially above $600^{\circ} \mathrm{C}$, as the bond strength between the fibre and the concrete diminishes considerably (Fig. 7a-c).

The results from the pull-out tests are also presented in Table 4, which includes the maximum pull-out load $\left(P_{\max }\right)$, the corresponding slip at $P_{\max }\left(S_{\max }\right)$, the maximum tensile stress induced in the fibre $\left(\sigma_{f, \max }\right)$ and the total amount of work done in the pull-out $\left(W_{\text {total }}\right)$, which is calculated as the area under the pull out load-slip curve for each concrete type at each temperature. It can be seen that the $P_{\max }, \sigma_{f, \max }$ and $W_{\text {total }}$ of the $4 \mathrm{DH}$ fibres at ambient temperature increases as the matrix compressive strength increases, as expected. At ambient temperature, the highest levels of bond strength are found for the HSC and UHPM samples, leading to significantly higher values for $P_{\max }, \sigma_{f, \max }$ and $W_{\text {total }}$ compared with the other mixtures.

With heating to $100^{\circ} \mathrm{C}$ and above, all four matrixes experienced loss in pull-out strength with temperature. The maximum pull-out load $\left(P_{\max , T}\right)$ normalised by the corresponding ambient value $\left(P_{\max }\right)$ for all mixtures with increasing temperature is presented in Fig. 8, whilst the corresponding maximum tensile stress induced in the fibre $\left(\sigma_{f, \max }\right)$, which is found identical to 
that of the $P_{\max }$, is also shown in Fig. 8. It can be clearly seen that the maximum pull-out load in all four matrixes is similar within the temperature range of 20 to $400^{\circ} \mathrm{C}$. For NSC, the $P_{\max }$ initially remains constant up to $300^{\circ} \mathrm{C}$ and then slightly reduces up to $400^{\circ} \mathrm{C}$. The $P_{\max }$ of MSC also remains constant at $100^{\circ} \mathrm{C}$ initially before decay at $200^{\circ} \mathrm{C}$ and then regains to maximize at $300^{\circ} \mathrm{C}$. The $P_{\max }$ of the $\mathrm{HSC}$ decreases at $100^{\circ} \mathrm{C}$ initially and then maximizes at $200^{\circ} \mathrm{C}$ before remains constant between 300 and $400^{\circ} \mathrm{C}$. In the case of UHPM, $P_{\max }$ increases up to $200^{\circ} \mathrm{C}$ initially and then gradually reduces leading to explosive spalling at $500^{\circ} \mathrm{C}$. The enhancement of bond strength in UHPM up to $200^{\circ} \mathrm{C}$ may be attributed to accelerate the pozzolanic reactions, improving packing density and reducing the pore size which improves the fibre-matrix interfacial properties. In this temperature range (i.e. $20-200^{\circ} \mathrm{C}$ ), as stated before, the pull-out load dropped suddenly for slip less than $5 \mathrm{~mm}$ indicating that the fibre ruptured internally at its hook. This represents $\sigma_{f, \max } / \sigma_{u t s}$ of around $0.97-1.0$ (where $\sigma_{u t s}=1500$ MPa is the ultimate tensile strength of the steel fibre), which reflects full activation of the mechanical bond i.e. the fraction of UTS absorbed by hinge formation.

At a temperature greater than $400^{\circ} \mathrm{C}$ the pull-out strength drops consistently with increase in temperature. The loss of bond strength in each concrete matrix almost followed a similar trend up to $700^{\circ} \mathrm{C}$. Once the target temperature reaches $800^{\circ} \mathrm{C}$, the $P_{\max }$ of NSC, MSC and HSC was only $52 \%, 25 \%$ and $31 \%$ of its original $P_{\max }$ value at ambient temperature, respectively. This sharp degradation of pull-out strength can be attributed to the decomposition of concrete due to complete dehydration and progression of micro and macro cracks, which had adverse effect on the compressive strength.

For NSC, MSC, HSC and UHPM, the quadratic relationship between the relative maximum pull-out load $P_{\max , T} / P_{\max }$ and the temperature $T$ can be expressed as Eq. (1). 
$218 \quad \frac{P_{\max , T}}{P_{\max }}=\frac{\sigma_{\max , T}}{\sigma_{\max }}=\left\{\begin{array}{c}0.98+3.52 \times 10^{-4} T-1.29 \times 10^{-6} T^{2}, \quad N S C \\ 0.96+4.44 \times 10^{-4} T-1.67 \times 10^{-6} T^{2}, \quad M S C \\ 0.99+4.56 \times 10^{-4} T-1.78 \times 10^{-6} T^{2}, \quad H S C \\ 0.99+4.70 \times 10^{-4} T-2.21 \times 10^{-6} T^{2}, \quad \text { UHPM }\end{array}, \quad 20^{\circ} \mathrm{C}<T \leq 800^{\circ} \mathrm{C}\right\}$

where, $P_{\max , T}$ and $P_{\max }$ represent the maximum pull-out load at elevated temperatures and maximum pull-out load at room temperature and $T$ elevated temperature correspondingly $\sigma_{\max , T} / \sigma_{\max }$ is the ratio of maximum pull-out stress between elevated and ambient temperature. As can be seen from Fig. 8 that the proposed empirical relations by Eq. (1) fit well with test data and the correlation coefficient $\mathrm{R}^{2}$ for NSC, MSC, HSC and UHPM were $0.96,0.96,0.95$ and 0.97 , respectively.

\subsubsection{Pull-out load-slip response of 5DH fibres.}

The average pull-out load-slip curves obtained from the pull-out test of 5DH fibre embedded in NSC, MSC, HSC and UHPM under different exposure temperatures $\left(20-800^{\circ} \mathrm{C}\right)$ are presented in Fig. 9a-d. It can be seen that the pull-out curves of 5DH fibre for all four matrixes are similar to the corresponding curves of 4DH fibre (Fig. 7a-d), even at higher temperatures, although with higher maximum pull-out load, slip capacity and total pull-out work values, particularly for HSC and UHPM. It should also be noted that the 5DH fibre pulled from all matrixes did not exhibit abrupt load drop or fibre rupture during the pull-out process.

The initial gradients of 5DH fibre curves embedded in all matrixes are similar to each other. However, the post-peak behaviour of the 5DH fibre pulled from the NSC and MSC (Figs. 9a and b) is significantly different from those of the HSC and UHPM (Figs. 9c and d). The postpeak behaviour of the fibre pulled from the NSC and MSC exhibit additional peak points and more variability, while the curves corresponding to HSC and UHPM show relatively 
smoother and lower residual pull-out strength. These differences may be attributed to the

241 frictional effect of coarse aggregate, together with the remaining irregularities due to incomplete deformation and straightening of the hook in the NSC and MSC (Fig. 10a), which ultimately increase the residual pull-out strength. While the lower residual strength of 5DH fibre pulled from HSC and UHPM can be attributed to the high level of deformation and straightening of the hook, which leads to the fibre pulled out under relatively low frictional resistance (Fig. 10b).

Table 5 summarizes the pull-out test results including the maximum pull-out load $\left(P_{\max }\right)$, the corresponding slip at $P_{\max }\left(S_{\max }\right)$, the maximum tensile stress induced in the fibre $\left(\sigma_{f, \max }\right)$ and the total amount of work done in the pull-out $\left(W_{\text {total }}\right)$, which are calculated as the average of three tests at each temperature. It can be seen that, as expected, as the compressive strength of the matrix increases (i.e. from NSC to MSC, HSC and UHPM), both the maximum pull-out load and the pull-out work done also increase significantly. After exposure to elevated temperature, there is a gradual decrease in both $P_{\max }$ and $W_{\text {total }}$ with increasing temperature for all concrete types. Fig. 11 shows the variation in maximum pull-out load at elevated temperature $\left(P_{\max , T}\right)$ normalised by the corresponding values at ambient temperature $\left(P_{\max }\right)$ with increasing temperature. The corresponding maximum tensile stress ratio induced in the fibre $\left(\sigma_{f, \max }\right)$, which is geometrically identical to that of the load ratio $P_{\max }$, is also shown in Fig. 11. It is apparent that there was no significant change in maximum pull-out load within the temperature range of 20 to $400^{\circ} \mathrm{C}$, but a subsequent gradual decrease in $P_{\max }$ when the temperature exceeds $400^{\circ} \mathrm{C}$. For NSC, there is an increase in $P_{\max }$ between 20 and $300^{\circ} \mathrm{C}$ and then gradually decreases with temperature up to $800^{\circ} \mathrm{C}$. The $P_{\max }$ of MSC slightly reduced at $100^{\circ} \mathrm{C}$ and remained almost constant between 200 and $400^{\circ} \mathrm{C}$ before it reduced sharply in the temperature range of $400-800^{\circ} \mathrm{C}$. The $P_{\max }$ of $\mathrm{HSC}$ increased linearly until $300^{\circ} \mathrm{C}$, then gradually decayed up to $500^{\circ} \mathrm{C}$ and finally sharply decreased in the temperature range of 500- 
follows an almost similar trend at high temperatures. Their $P_{\max }$ was sharply reduced at a

267 similar way above $400^{\circ} \mathrm{C}$, especially for MSC and $\mathrm{HSC}$. At $800^{\circ} \mathrm{C}$, the $P_{\max }$ of NSC, MSC and HSC were only $45 \%, 25 \%$ and $16 \%$ of its original $P_{\max }$ value at ambient temperature, respectively. In the case of UHPM, there is reduction in $P_{\max }$ at $100^{\circ} \mathrm{C}$ initially, and then $P_{\max }$ regains to maximize at $200^{\circ} \mathrm{C}$ and finally decays sharply up to $400^{\circ} \mathrm{C}$.

For NSC, MSC, HSC and UHPM, the quadratic relationship between the relative maximum pull-out load $P_{\max , T} / P_{\max }$ and the temperature $T$ is given by Eq. (2).

$$
\frac{P_{\max , T}}{P_{\max }}=\frac{\sigma_{\max , T}}{\sigma_{\max }}=\left\{\begin{array}{l}
1.05-2.56 \times 10^{-5} T-1.06 \times 10^{-6} T^{2}, \quad N S C \\
0.95+9.05 \times 10^{-4} T-2.35 \times 10^{-6} T^{2}, \quad M S C, 20^{\circ} \mathrm{C}<T \leq 800^{\circ} \mathrm{C} \\
0.99+8.87 \times 10^{-4} T-2.55 \times 10^{-6} T^{2}, \quad H S C
\end{array}\right\}
$$

Where, $P_{\max , T}$ and $P_{\max }$ represent the maximum pull-out load at elevated temperatures and maximum pull-out load at room temperature and $T$ elevated temperature. It can be seen in Fig. 11 that the curves proposed by Eq. (2) fit well with test data, except that for UHPM. The fit to UHPM was not considered over this temperature range with its $500^{\circ} \mathrm{C}$ temperature limit. For NSC, MSC and HSC, the correlation coefficient $\mathrm{R}^{2}$ were $0.90,0.96$ and 0.94 respectively.

\subsection{Difference in the pull-out behaviour of $4 D H$ and $5 D H$ fibres}

To further understand the influence of the hook geometry and elevated temperature on the pull-out response, a comparison of two fibres pulled from a different matrix were made. The comparison of the maximum pull-out load between the two hooked end fibres after exposure to various levels of elevated temperature $\left(20-800^{\circ} \mathrm{C}\right)$ are plotted in Fig. 12 . It is evident that the pull-out behaviour of the $5 \mathrm{DH}$ fibre embedded in all matrixes is similar to that of the 
corresponding 4DH fibre, but different in their $P_{\max }$ and $W_{\text {total }}$ values. It can be seen from Fig. 12 that as the compressive strength of the matrix increases, both the maximum pull-out load and pull-out work increase significantly for both fibres. Also from Fig. 12a it is interesting to observe that the maximum pull-out load of 4DH fibres from the NSC is higher than the corresponding values of the $5 \mathrm{DH}$ fibres for all temperatures. This behaviour may be attributed to the fact that the $5 \mathrm{DH}$ fibre requires high energy (i.e. high matrix strength) to straighten the hook having a high mechanical anchorage compared to $4 \mathrm{DH}$ fibres. With the further increase in compressive strength from NSC $\left(f_{c}=33 \mathrm{MPa}\right)$ to $\mathrm{MSC}\left(f_{c}=54 \mathrm{MPa}\right)$ and HSC $\left(f_{c}=71 \mathrm{MPa}\right)$, the maximum pull-out load of $5 \mathrm{DH}$ fibre increased much more than that of 4DH fibres (Figs. 12b and c). This indicates that good bond between steel fibre and matrix due to high mechanical interlocking and high matrix strength is necessary to straighten the hook. However, this effect has a short duration since both fibres behave similarly especially at higher temperatures (i.e. above $600^{\circ} \mathrm{C}$ ). Comparing the two fibres embedded in UHPM (Fig. $12 \mathrm{~d}$ ), the maximum pull-out load of $5 \mathrm{DH}$ is also higher than that of the $4 \mathrm{DH}$ fibres and it maximized at $200^{\circ} \mathrm{C}$ for both fibres in which $5 \mathrm{DH}$ fibre is more effective.

The comparison of the total pull-out work between the two hooked end fibres after different peak temperatures $\left(20-800^{\circ} \mathrm{C}\right)$ is plotted in Fig 13 . It can be observed that there is no clear variation between the two fibres in total pull-out work of NSC with different elevated temperatures (Fig. 13a). The highest $\mathrm{W}_{\text {total }}$ observed for $4 \mathrm{DH}$ fibre after heating to $500^{\circ} \mathrm{C}$ which is almost two times higher than the others (Table 4). This inconsistency may be a result of the variability in the deformation required to straighten the hook. As the MSC as an example, the mechanical anchorage contribution provided by the $5 \mathrm{DH}$ fibre gave rise to a significant increase in the $\mathrm{W}_{\text {total }}$ compared to $4 \mathrm{DH}$ fibre (Fig. 13b), although the $\mathrm{W}_{\text {total }}$ of $5 \mathrm{DH}$ fibre was greatly reduced for specimens heated to temperatures greater than $400^{\circ} \mathrm{C}$. 

and $800^{\circ} \mathrm{C}$ (Fig. 13c). It is noteworthy that since the concrete strength of NSC, MSC and HSC does not significantly change up to temperature of $500^{\circ} \mathrm{C}$ (Fig. 4). Therefore, the $\mathrm{W}_{\text {total }}$ of both fibres does not vary considerably. The higher values of $\mathrm{W}_{\text {total }}$ for both fibres at high temperatures may also be attributed to the presence of coarse aggregate in concrete together with the curvatures remaining at the fibre end. In case of UHPM, the $\mathrm{W}_{\text {total }}$ for $5 \mathrm{DH}$ fibre specimens is much higher than the corresponding values of $4 \mathrm{DH}$ fibre up to $300^{\circ} \mathrm{C}$. The lower values of $\mathrm{W}_{\text {total }}$ of the $4 \mathrm{DH}$ fibre can be attributed partly to the sudden load drop due to a partial fibre rupture in the 4DH geometry (Fig. 13d).

\section{Discussion}

Here we consider the most effective combination of matrix strength and fibre geometry for the various elevated temperatures investigated.

1) In the range of $20-400^{\circ} \mathrm{C}$ :

Due to the high mechanical anchorage of the 4DH fibre compared with its tensile strength $\left(f_{u t s}=1500 \mathrm{MPa}\right)$, the rupture of this fibre is more likely to occur in a matrix of high strength. That is, the fibre rupture tends to occur when the fibre with high mechanical anchorage and relatively low tensile strength is combined with very high matrix strength. This indicates that the mechanical anchorage contribution of 4DH fibre can be fully effective if fibre rupture is prevented. Therefore, the tensile strength of $4 \mathrm{DH}$ fibre has to increase in parallel with the strength of its anchorage. Only in this way can the fibre resist the forces acting upon it. On the basis of these considerations, it is believed that increasing the tensile strength of the 4DH fibre would effectively prevent fibre rupture and capitalize the end hook anchorage strength to the maximum degree. 
For the 5DH fibres, the following observations apply:

337 1) The complete deformation of fibre hook embedded in the NSC matrix did not occur. Rather only low level of deformation and straightening of the hook have been observed (Fig. 10a).

2) The partial deformation dramatically increased with increasing the matrix compressive strength.

3) The full deformation and straightening of 5DH fibre hook only takes place when the fibres are embedded in UHPM (Fig. 10b).

4) In all four matrixes, the 5DH fibre is completely pulled out from the specimen without any occurrence of the fibre rupture.

5) As a result of the 5DH unique hook's geometry and its high tensile strength a matrix with high compressive strength is needed to ensure the full extent of hook anchorage, which makes this type of fibre attractive for use in ultra-high performance cementitious composites. 6) Finally, the conclusion is drawn that the $5 \mathrm{DH}$ fibre used in this study may only be fully exploited as the reinforcement in UHPM.

2) In the higher temperature range between $400^{\circ} \mathrm{C}$ and $800^{\circ} \mathrm{C}$ :

For 4DH and 5DH fibres, the influence of concrete compressive strength plays an important role on the pull-out strength when the temperature exceeds $500^{\circ} \mathrm{C}$. It has been seen that these two fibres embedded in MSC and HSC have quite similar values of $P_{\max }$ throughout the (600$800^{\circ} \mathrm{C}$ ) temperature range (see Figs. $12 \mathrm{~b}$ and $\mathrm{c}$ ). This indicates that both fibres have almost similar bond strength when pulled from the matrix without their deformation and straightening resulting from the concrete strength degradation. 


\section{Conclusions}

360

361

362

The effect of elevated temperatures on the bond mechanisms associated with the pull-out behaviour of two types of hooked end steel fibres embedded in four different concrete mixes was thoroughly investigated. Some specific conclusions can be drawn as follows:

1) Temperature had a little influence on the compressive strength for all concrete specimens heated up to $400^{\circ} \mathrm{C}$. However, at temperatures higher than $400^{\circ} \mathrm{C}$, explosive spalling occurred for UHPM above $500^{\circ} \mathrm{C}$, while the compressive strength of NSC, MSC and HSC generally decreased with increasing temperature. Once the temperature reached $800^{\circ} \mathrm{C}$, the compressive strength of NSC, MSC and HSC was only $33 \%, 42 \%$ and $47 \%$ of its original strength at ambient temperature, respectively. The temperature induced degradation was related to the small mass loss. At the greatest temperature of $800^{\circ} \mathrm{C}$, the mass losses of NSC, MSC and HSC specimens were $11 \%, 10 \%$, and $8 \%$ of their original values, respectively.

2) The pull-out behaviour of $4 \mathrm{DH}$ and $5 \mathrm{DH}$ fibres appeared to be affected by elevated temperatures in a similar manor. The pull-out strength of both fibres did not vary significantly throughout $20-400^{\circ} \mathrm{C}$ temperature range, but within the temperature range of 500 to $800^{\circ} \mathrm{C}$, the maximum pull-out load decreased significantly for all concretes.

3) Pull-out strength was found to be strongly dependent on the hook geometry in which the mechanical anchorage contribution provided by the hook increased with matrix strength. The bond strength of 5DH fibre was considerably higher than that of 4DH fibre, except the case of NSC. However, the bond strength of both fibres diminished gradually with increasing temperature and both fibres embedded in MSC and HSC 
exhibited comparable maximum pull-out load values in the $600-800^{\circ} \mathrm{C}$ temperature range.

4) The reduction in pull-out strength of both fibres correlated very well with the corresponding decrease in compressive strength of the matrix.

\section{Acknowledgments}

The first author gratefully acknowledges the financial support of the Ministry of Higher Education and Scientific Research of Iraqi Government for this Ph.D. project.

Reference List

[1] B. Chen, J. Liu, Residual strength of hybrid-fiber-reinforced high-strength concrete after exposure to high temperatures, Cem. Concr. Res. 34 (2004) 1065-1069.

[2] V. Kodur, Properties of concrete at elevated temperatures, ISRN Civil Engineering. 2014 (2014).

[3] F. Aslani, B. Samali, Constitutive relationships for steel fibre reinforced concrete at elevated temperatures, Fire Technol. 50 (2014) 1249-1268.

[4] J.P. Romualdi, M. Ramey, S.C. Sanday, Prevention and Control of Cracking by Use of Short Random Fibers, Special Publication. 20 (1968) 179-204.

[5] Y. Ding, F. Zhang, F. Torgal, Y. Zhang, Shear behaviour of steel fibre reinforced selfconsolidating concrete beams based on the modified compression field theory, Composite Structures. 94 (2012) 2440-2449.

[6] M. Eik, J. Puttonen, H. Herrmann, An orthotropic material model for steel fibre reinforced concrete based on the orientation distribution of fibres, Composite Structures. 121 (2015) 324-336.

[7] S. Abdallah, M. Fan, X. Zhou, S. Geyt, Anchorage Effects of Various Steel Fibre Architectures for Concrete Reinforcement, International Journal of Concrete Structures and Materials. (2016) 1-11.

[8] A. Lau, M. Anson, Effect of high temperatures on high performance steel fibre reinforced concrete, Cem. Concr. Res. 36 (2006) 1698-1707. 
[9] P. Pliya, A. Beaucour, A. Noumowé., Contribution of cocktail of polypropylene and steel fibres in improving the behaviour of high strength concrete subjected to high temperature,

413 Constr. Build. Mater. 25 (2011) 1926-1934.

414 [10] K.K. Sideris, P. Manita, E. Chaniotakis, Performance of thermally damaged fibre

415 reinforced concretes, Constr. Build. Mater. 23 (2009) 1232-1239.

416 [11] R. Haddad, R. Al-Saleh, N.M. Al-Akhras, Effect of elevated temperature on bond 417 between steel reinforcement and fiber reinforced concrete, Fire Saf. J. 43 (2008) 334-343.

418 [12] S. Abdallah, M. Fan, D.W.A. Rees, Analysis and modelling of mechanical anchorage of 419 4D/5D hooked end steel fibres, Mater Des. 112 (2016) 539-552.

[13] G. Nammur Jr, A.E. Naaman, Bond stress model for fiber reinforced concrete based on bond stress-slip relationship, ACI Mater. J. 86 (1989).

[14] J. Won, J. Lee, S. Lee, Bonding behaviour of arch-type steel fibres in a cementitious composite, Composite Structures. 133 (2015) 117-123.

[15] J. Won, B. Hong, S. Lee, S.J. Choi, Bonding properties of amorphous micro-steel fibrereinforced cementitious composites, Composite Structures. 102 (2013) 101-109.

[16] J. Won, J. Lee, S. Lee, Predicting pull-out behaviour based on the bond mechanism of arch-type steel fibre in cementitious composite, Composite Structures. 134 (2015) 633-644.

[17] B. En, 197-1 (2000) Cement: composition, specifications and conformity criteria for common cements, British Standards Institution, London. (2000). 

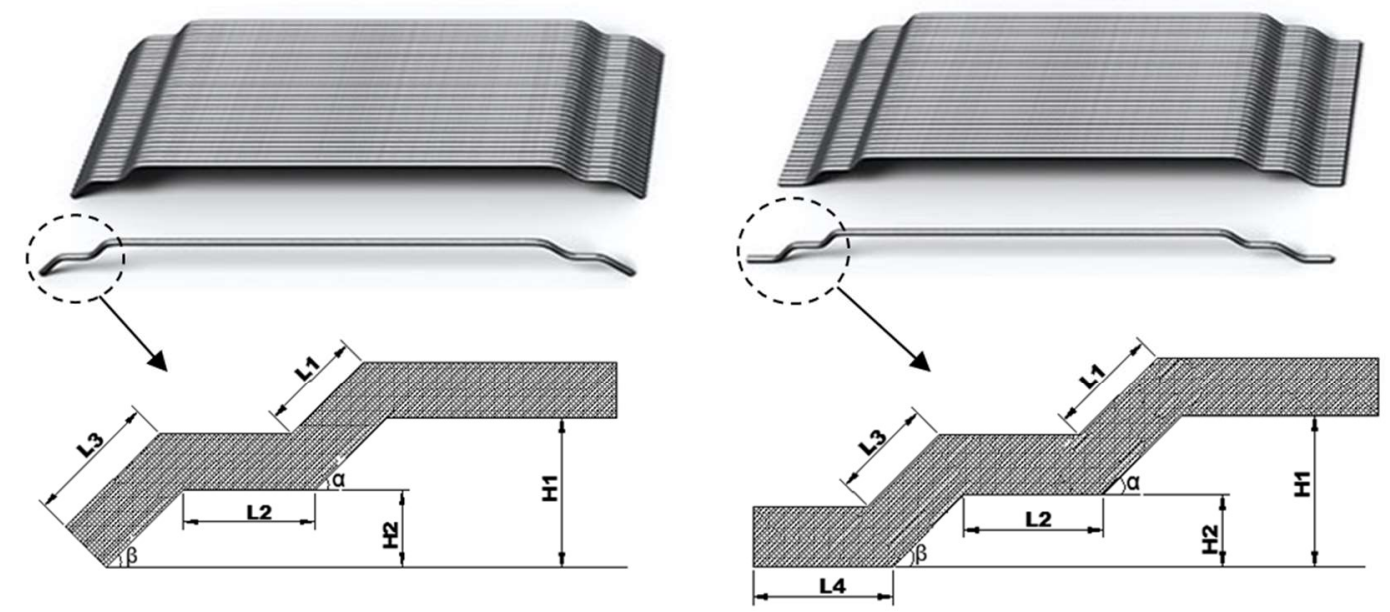

450

451

4D $65 / 60 \mathrm{BG}$

$5 \mathrm{D} 65 / 60 \mathrm{BG}$

452

453

Fig. 1. Geometrical properties of 4DH and 5DH fibres

454

455

456

457

458

459

460

461

462

463

464

465

466

467

468

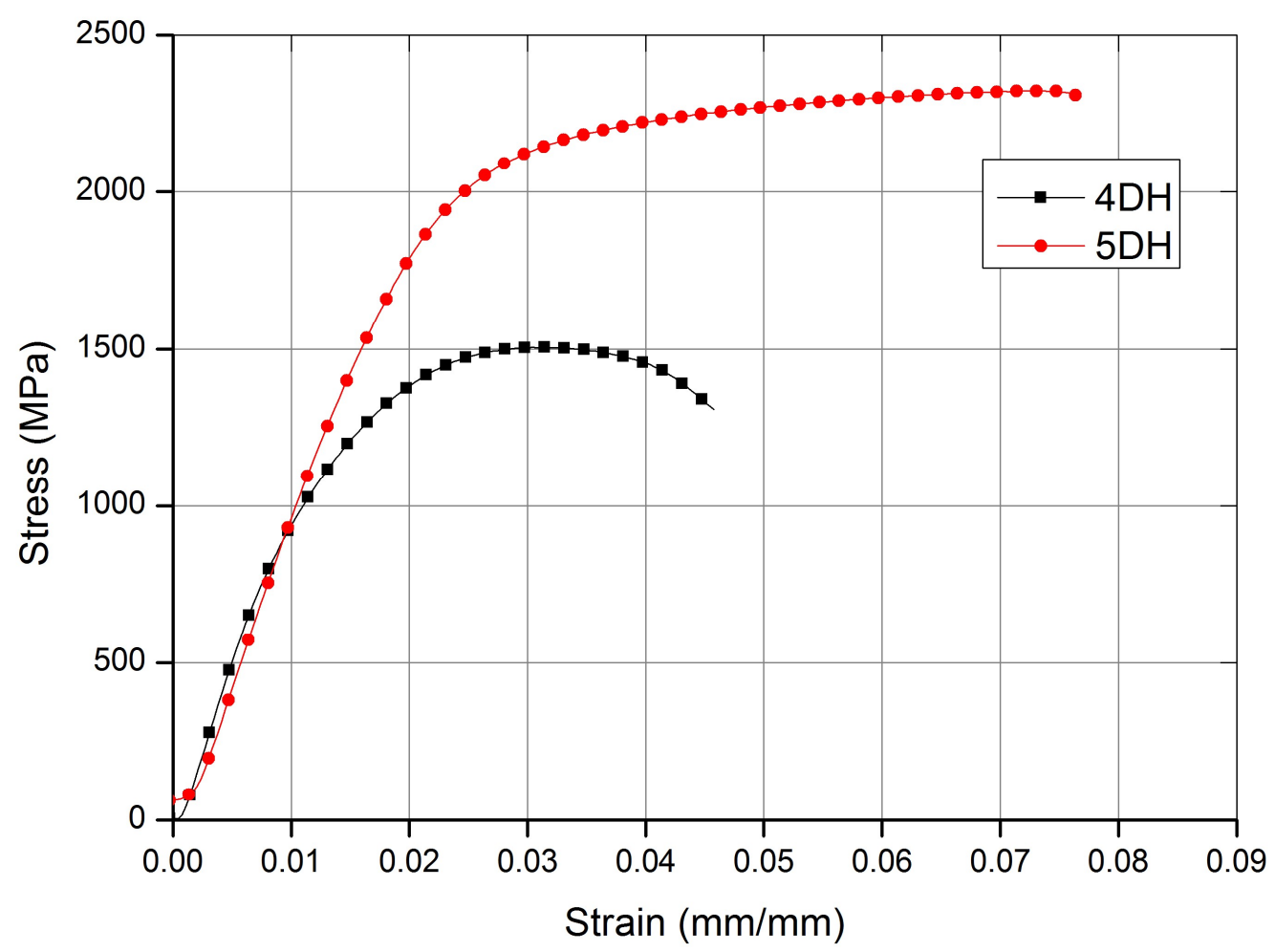

469

Fig. 2. Stress-strain curve for fibres tensile tests. 


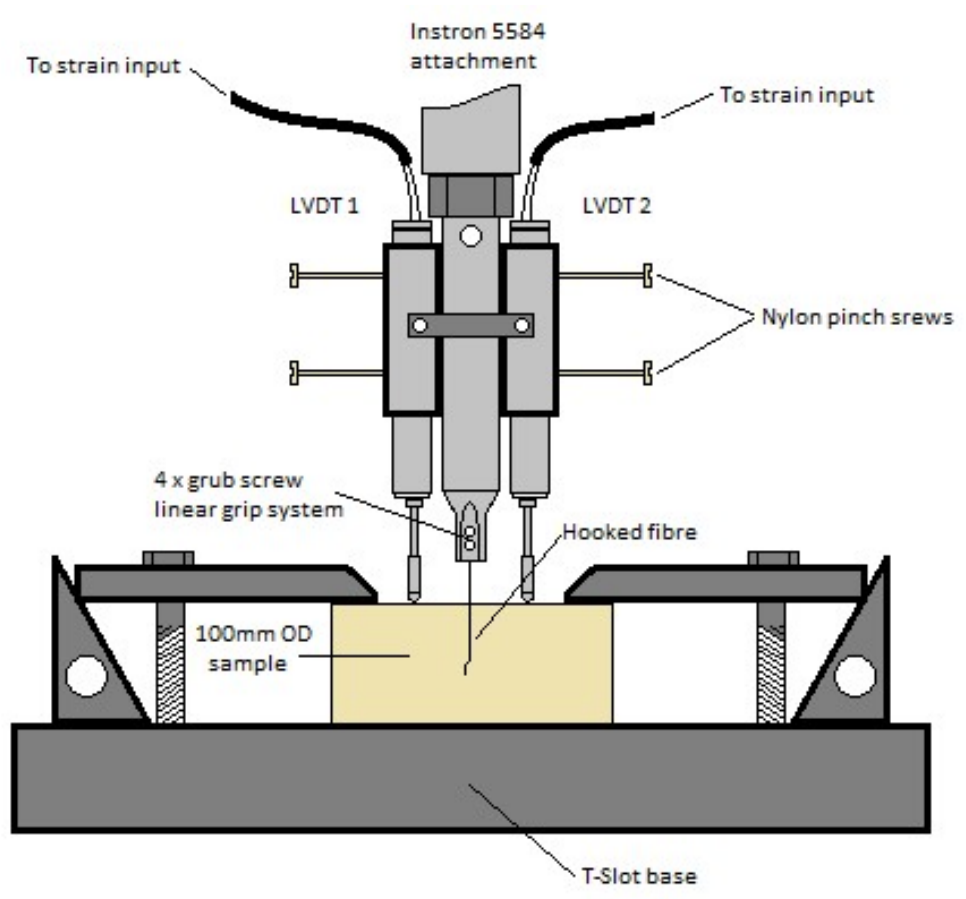

480

Fig. 3. Pull-out test setup.

482

483

484

485

486

487

488

489

490

491

492

493

494

495

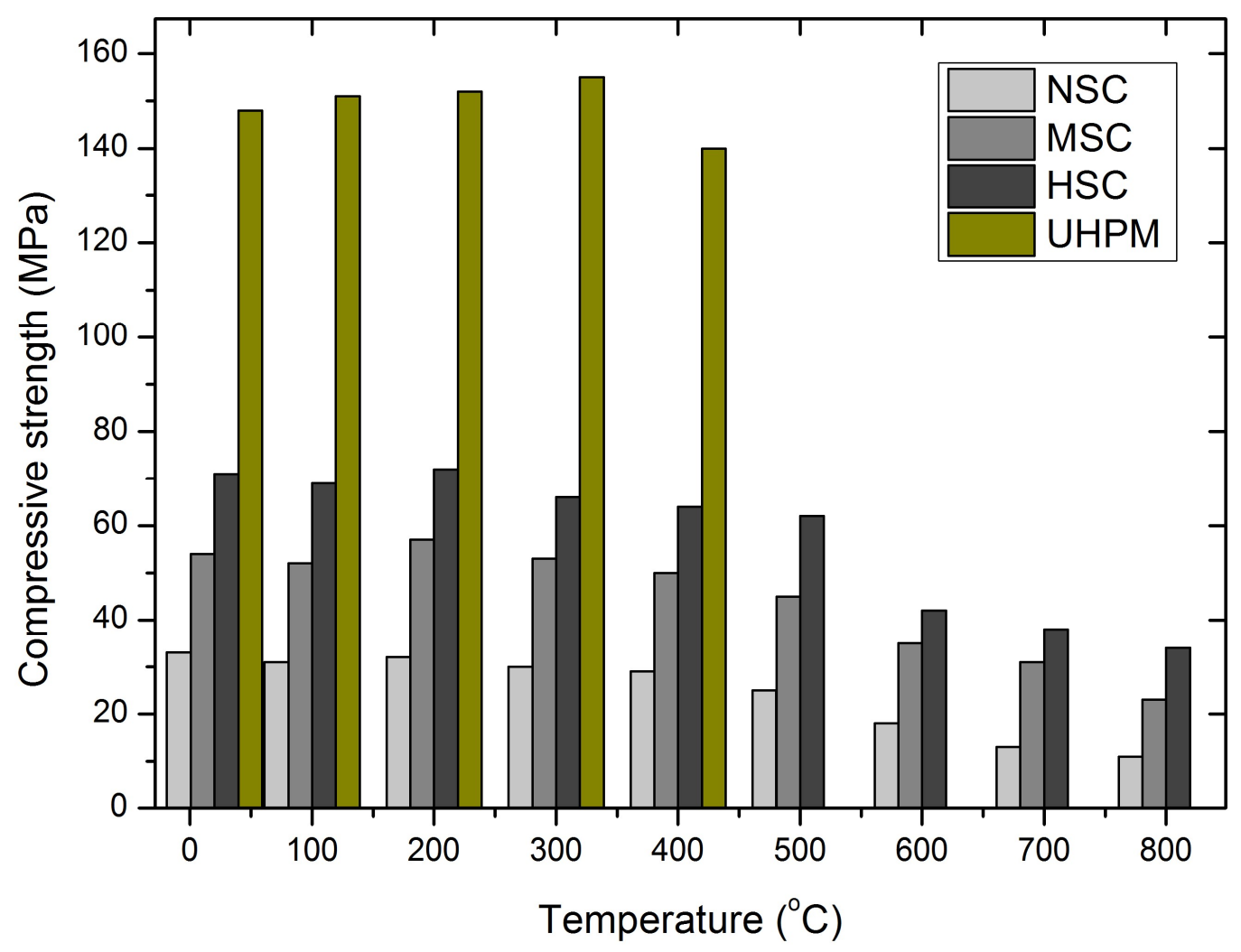

496

Fig. 4. Effect of temperature on compressive strength. 


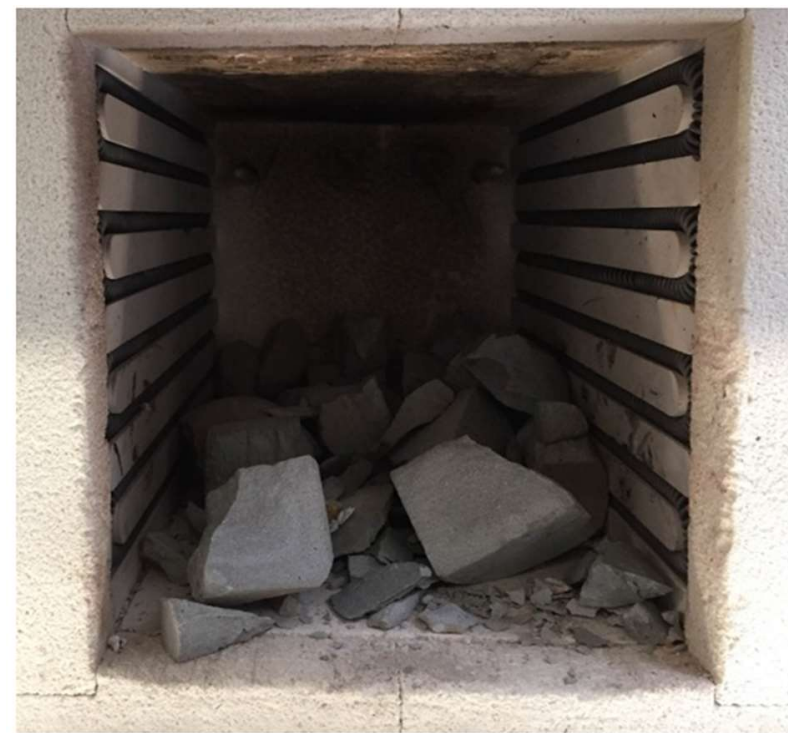

(b) $\mathrm{UHPM}-500^{\circ} \mathrm{C}$

Fig. 5. Failure mode of NSC and UHPM after exposure to high temperatures.

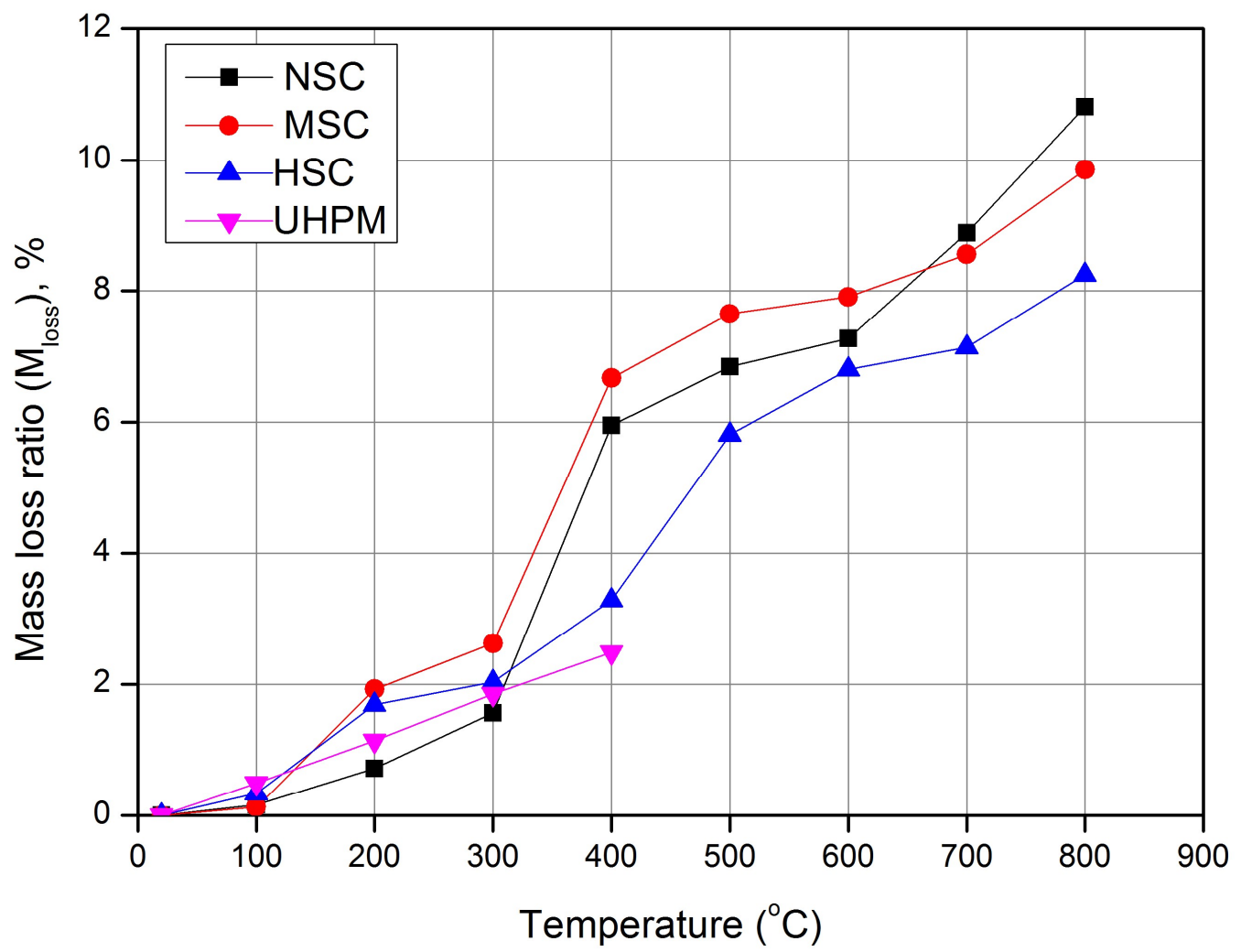

521

522 Fig. 6. Relationship between elevated temperature and mass loss for the four concrete mixes. 

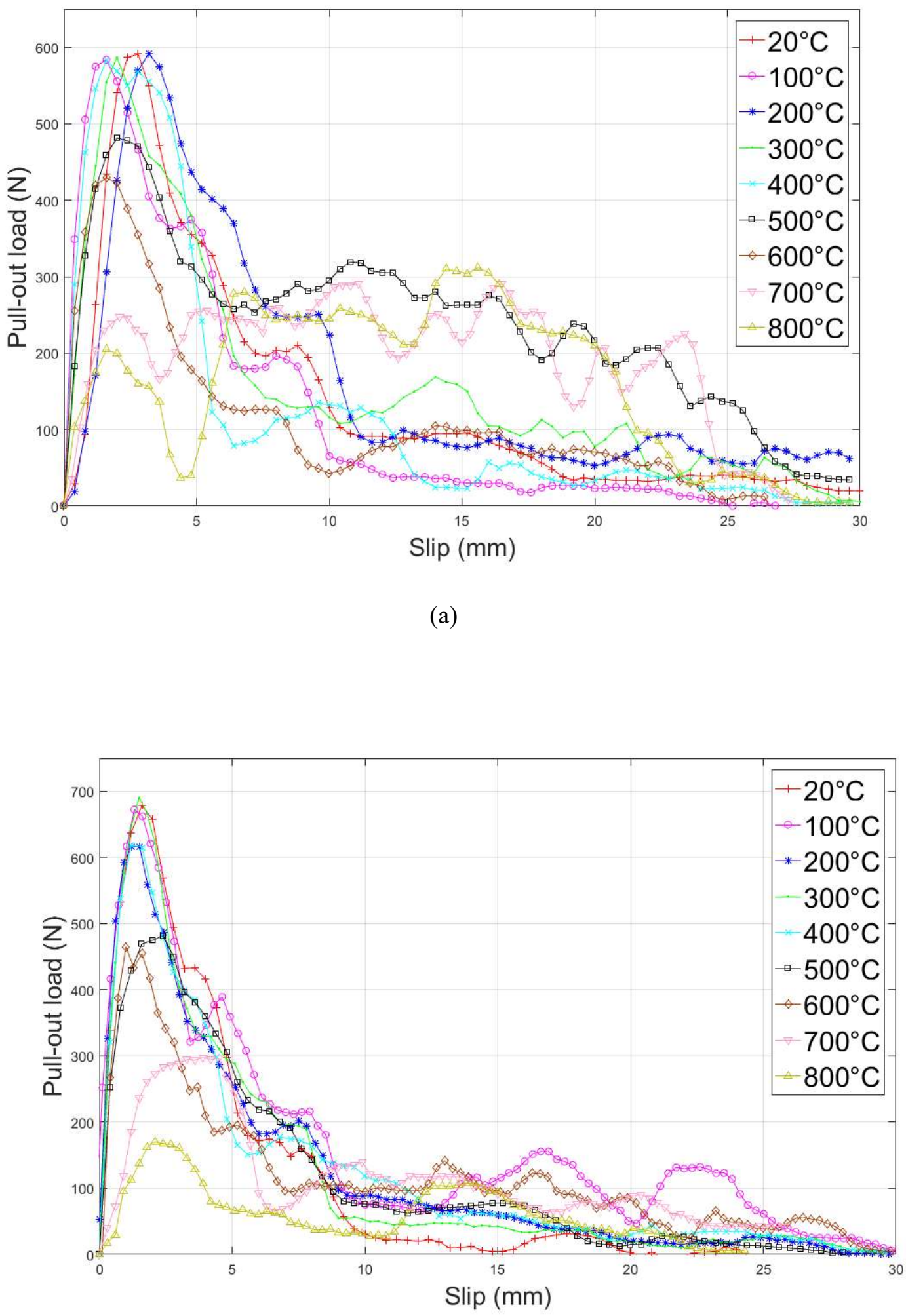

(b) 


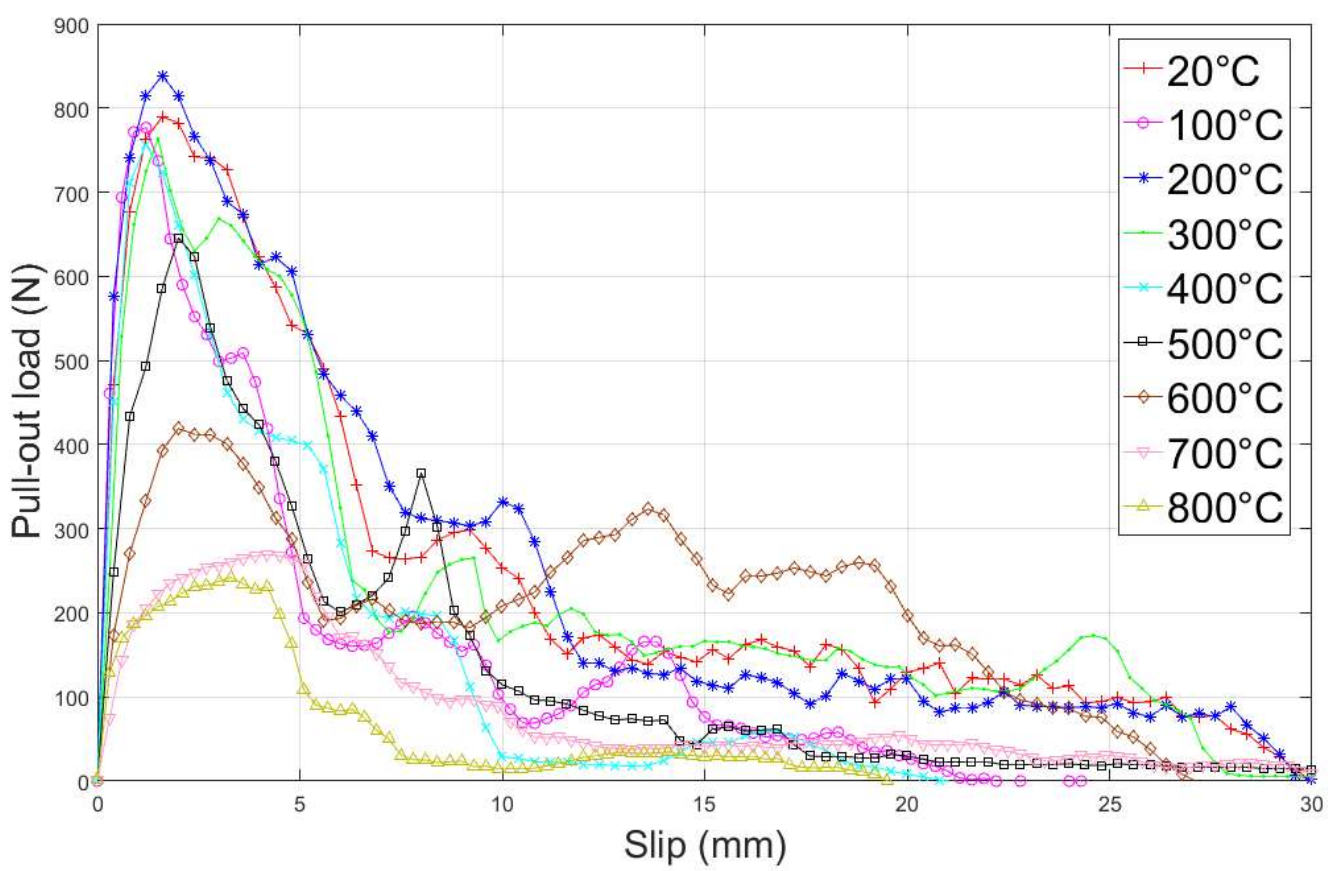

542

543

544

545

546

547

548

549

550

551

552

553

554

555

556

557

558 (c)

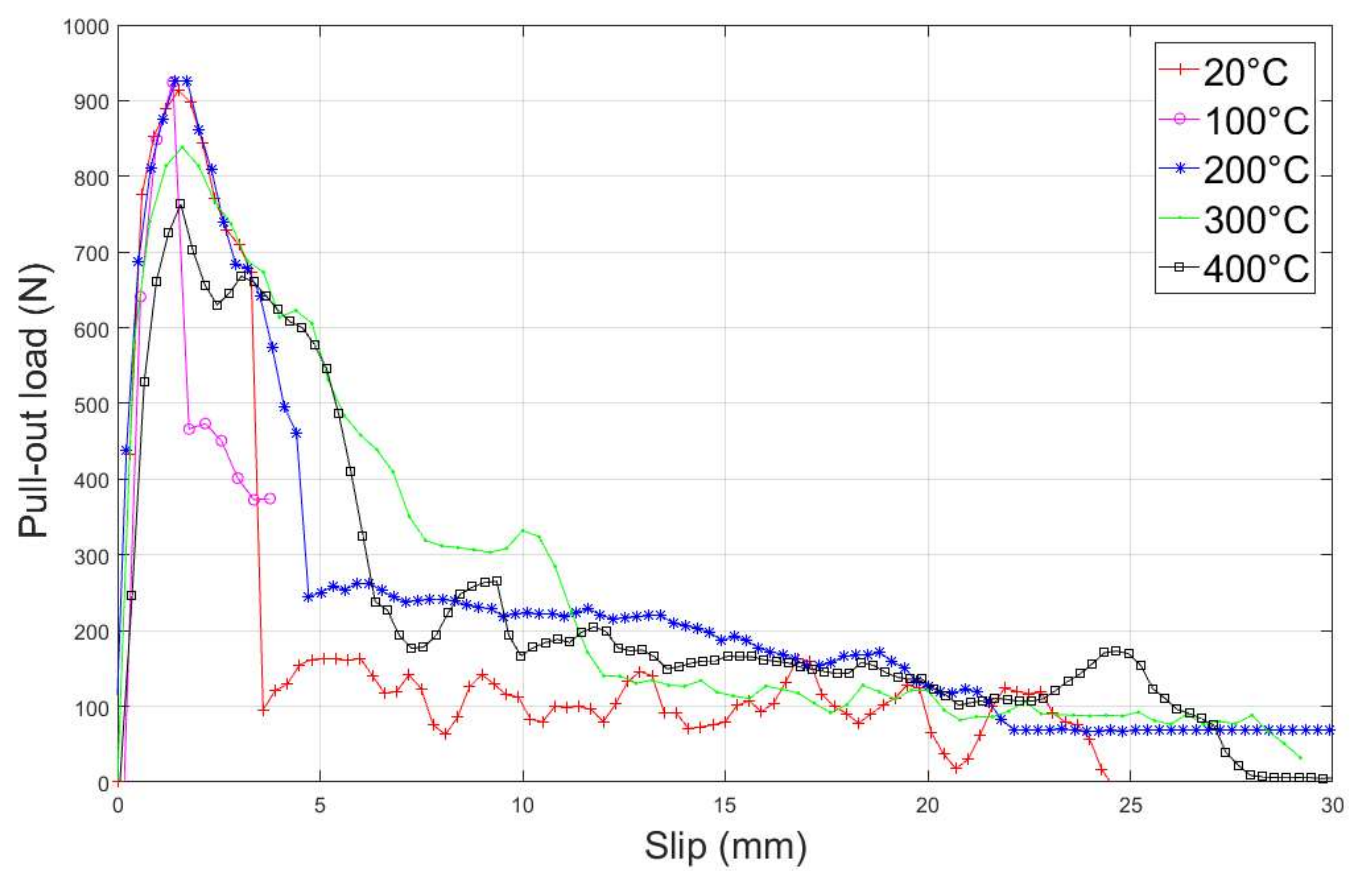

(d)

Fig. 7. Pull-out load-slip curves obtained from pull-out test of 4DH fibre. (a) NSC, (b) MSC, (c) HSC and (d) UHPM. 


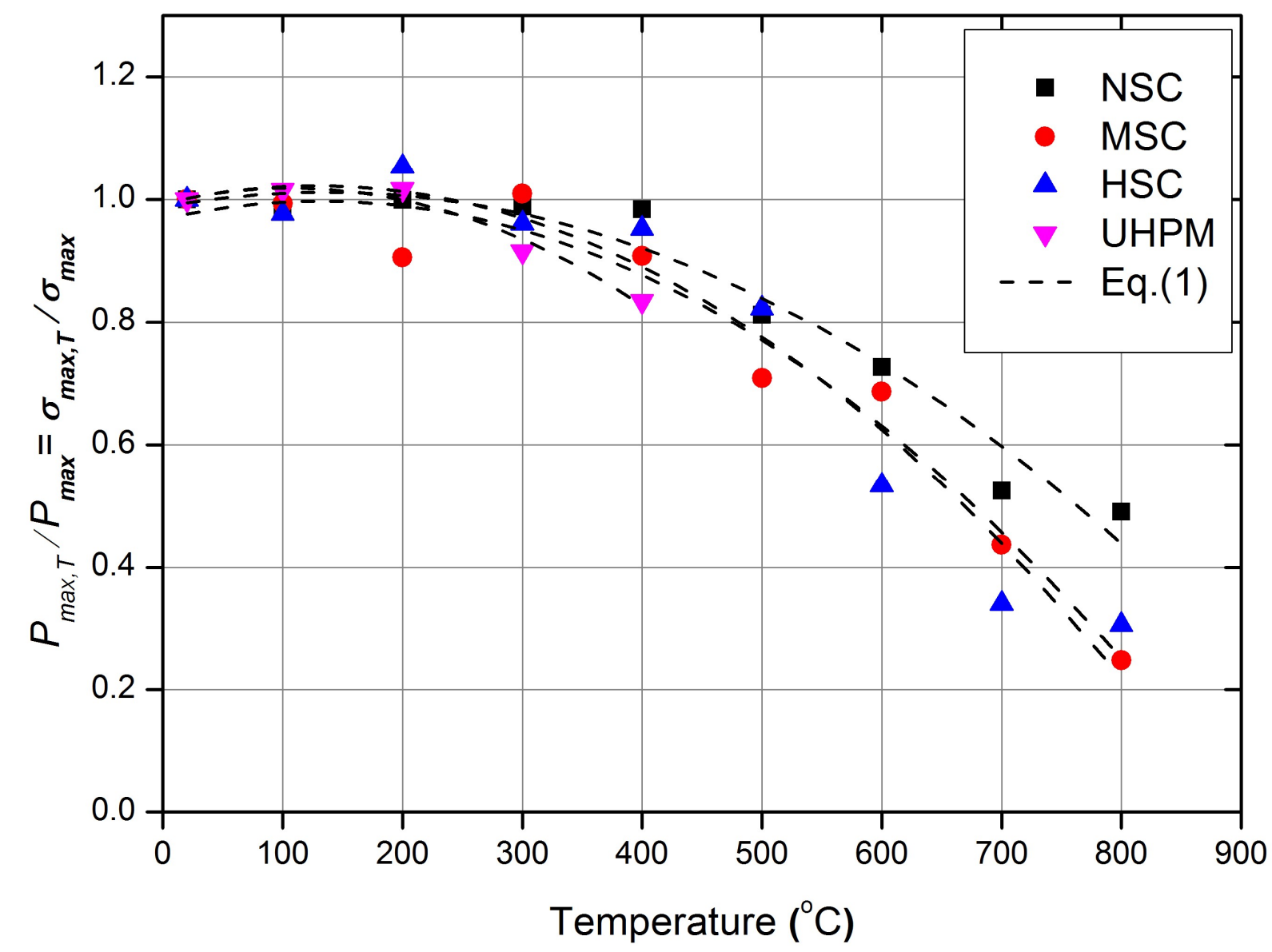

74

6

7

78

79

80

81

82

Fig. 8. Variation in maximum pull-out load and stress of 4DH fibre as a function of temperature.

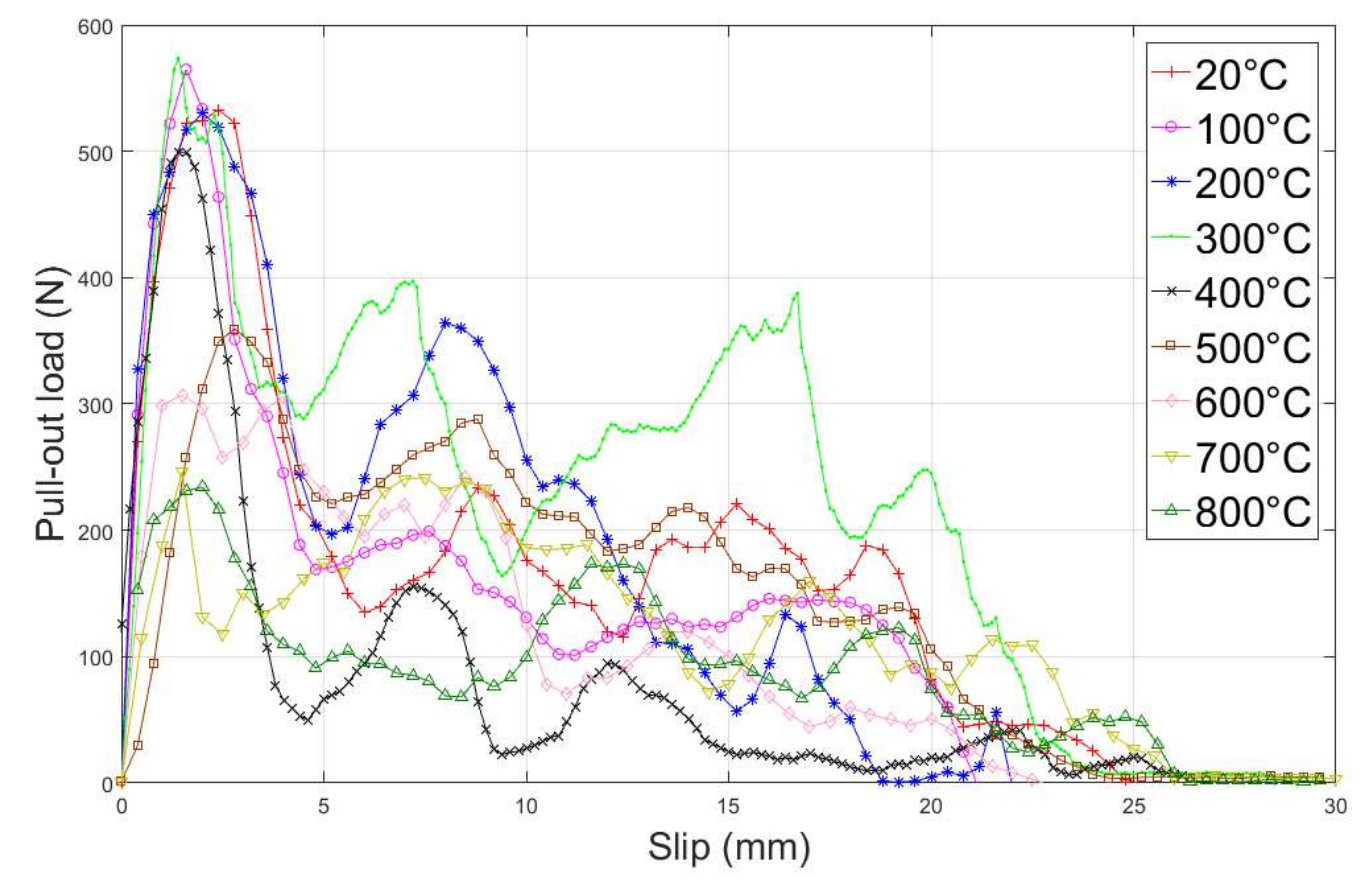

587 


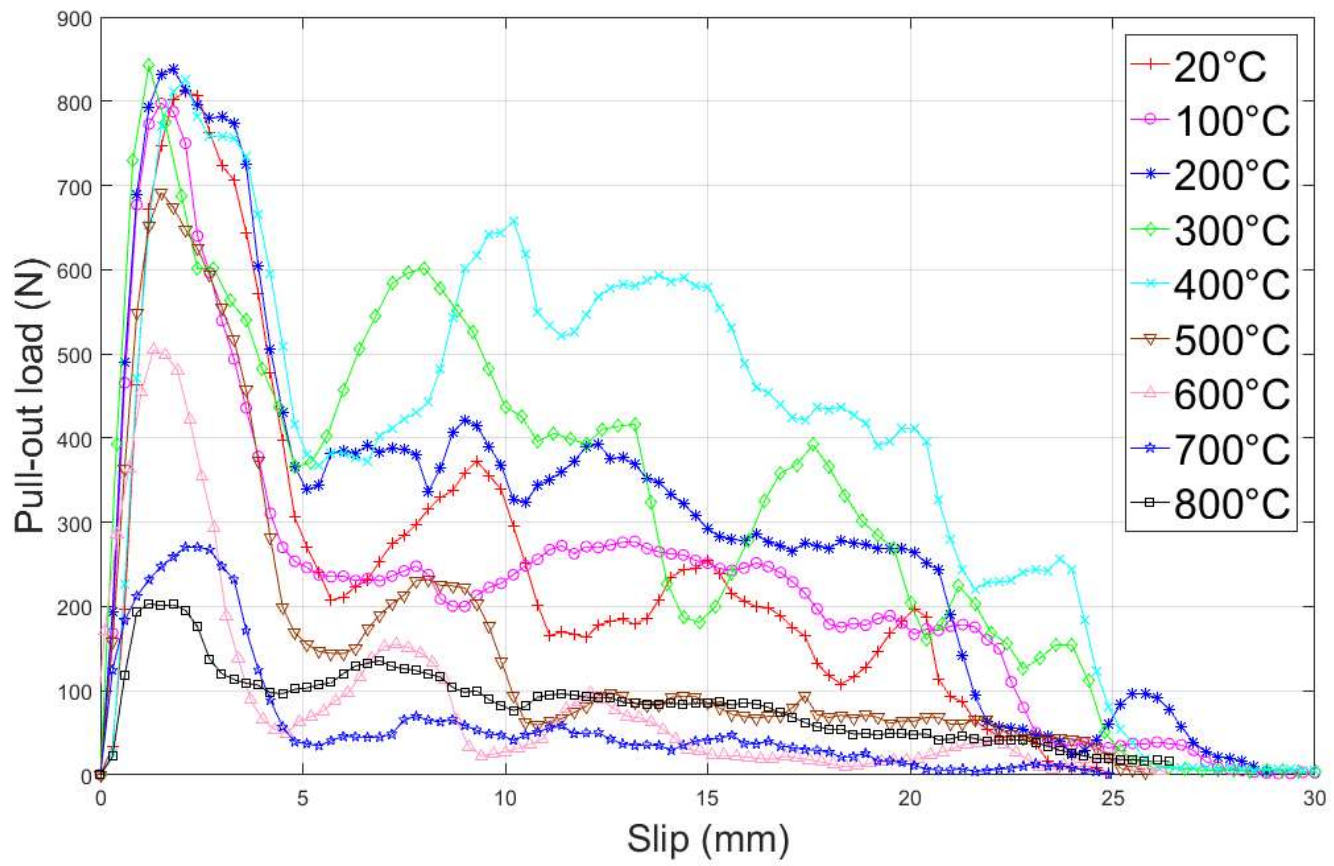

601

602

603

604

605

606

607

608

609

610

611

612

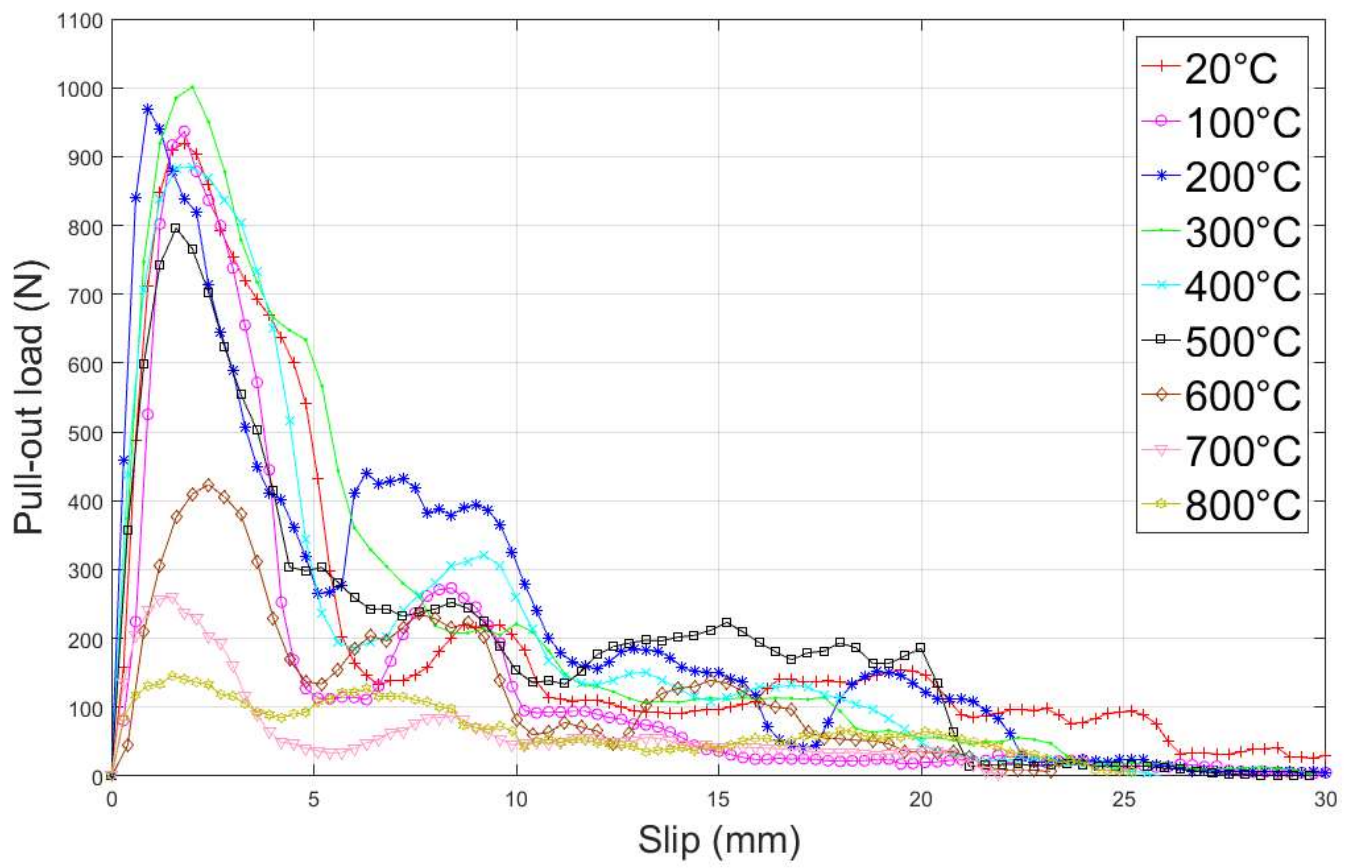

613 
Fig. 9. Pull-out load-slip curves obtained from pull-out test of 5DH fibre. (a) NSC, (b) MSC,

630

631

632

633

634

635

636

637

638

639

640

641

642

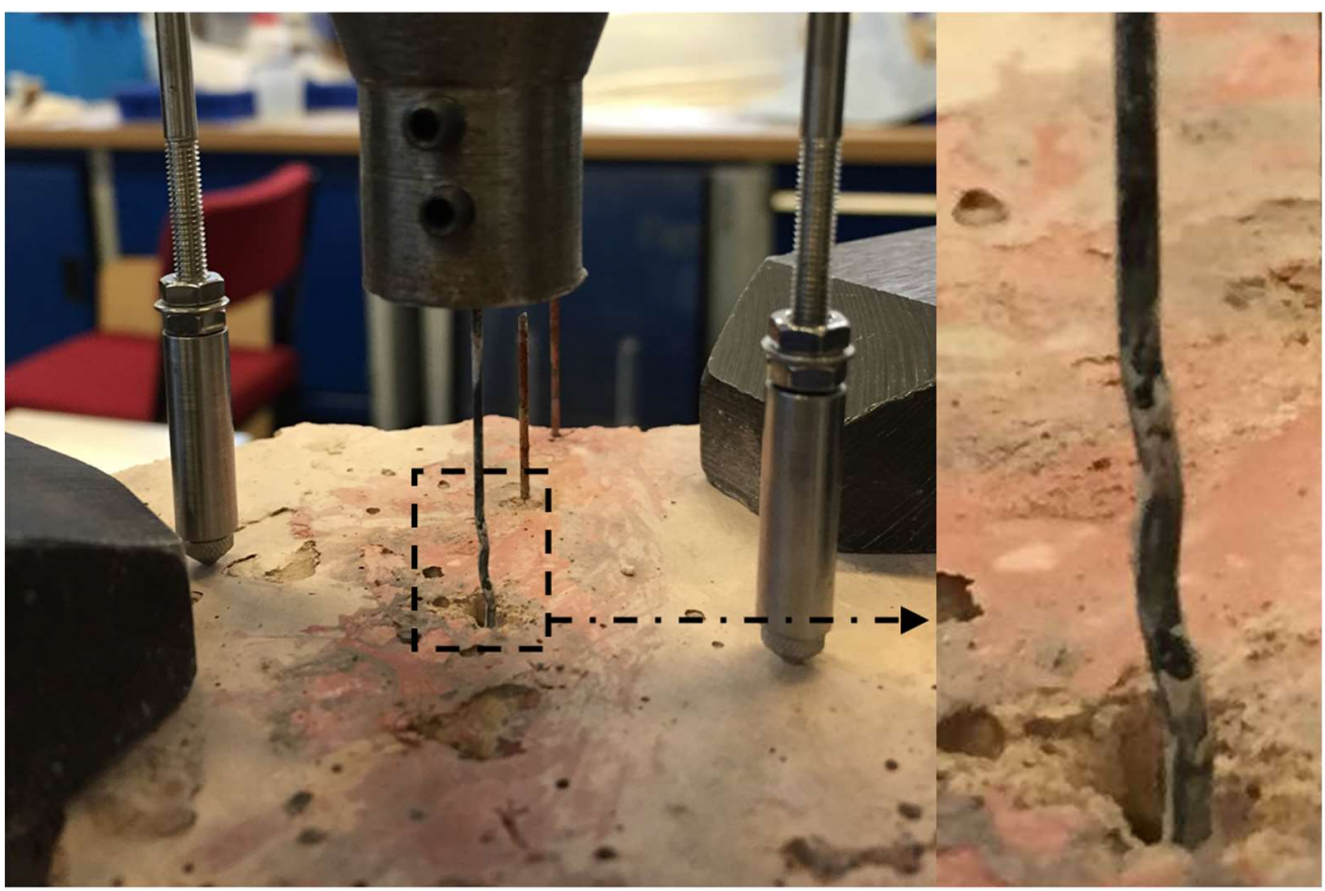

(a)

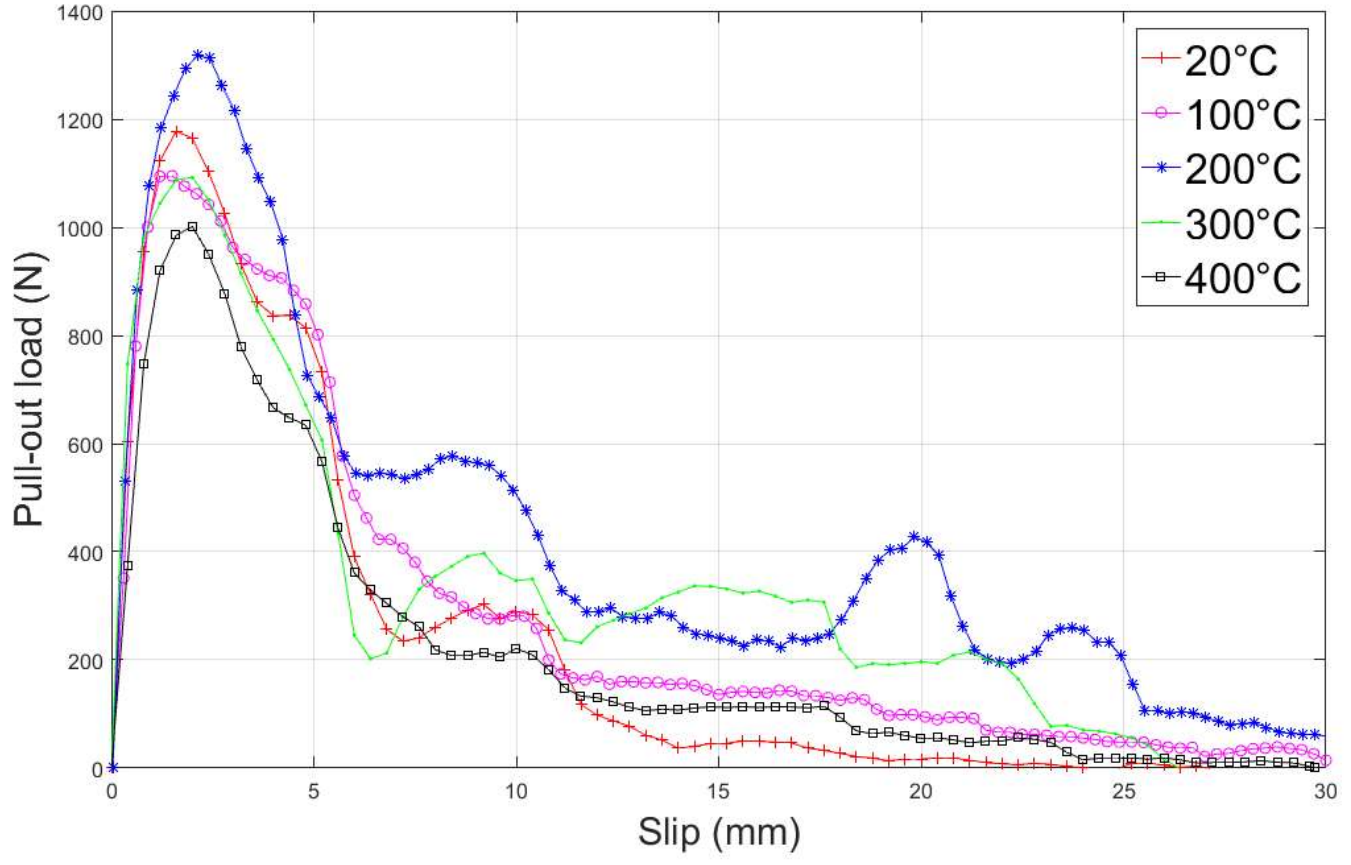

(d)

(c) HSC and (d) UHPM.

643 


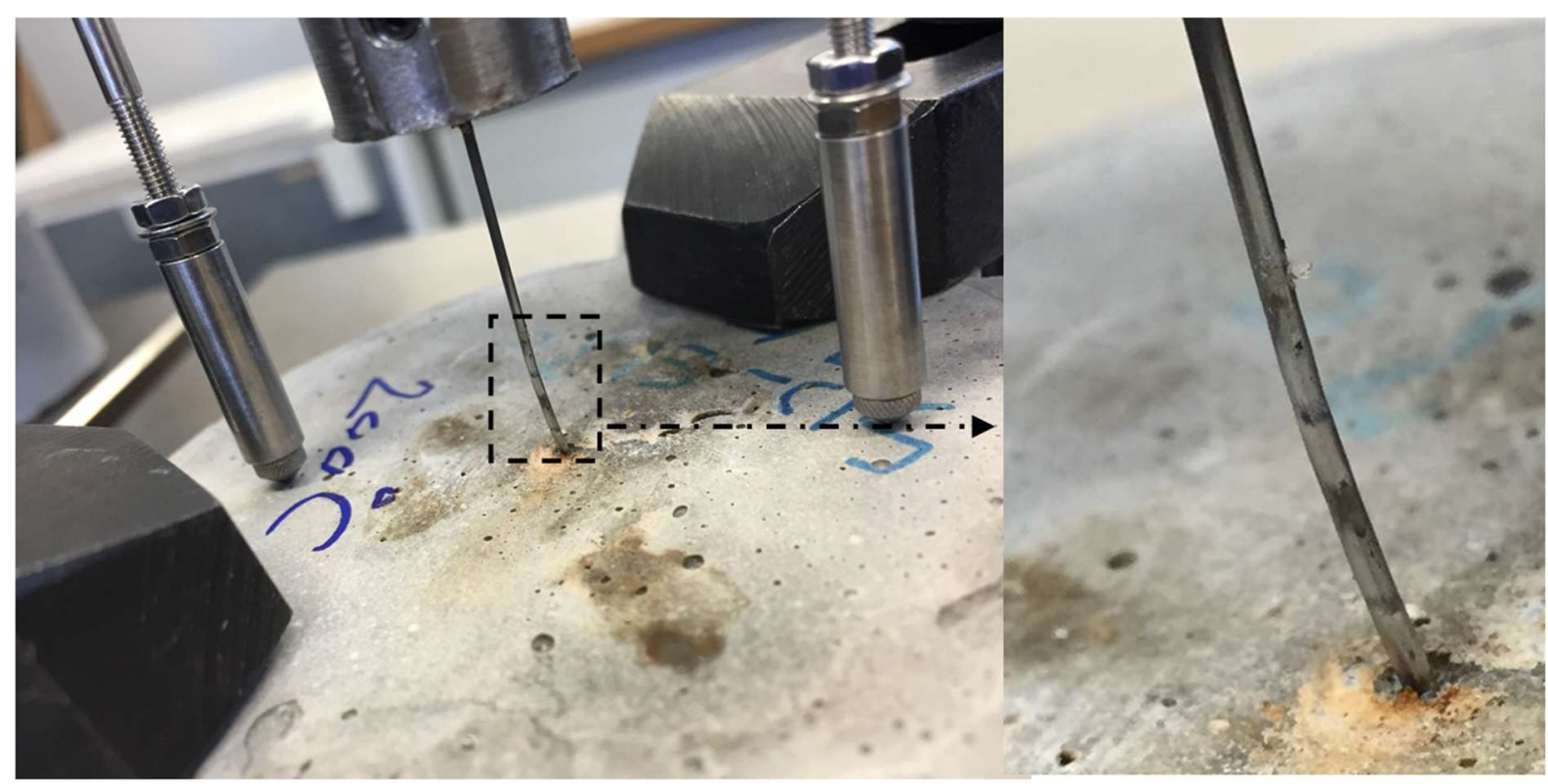

(b)

656

Fig. 10. Deformation and straightening of 5DH after pull-out test. (a) NSC and

659

660

661

662

663

664

665

666

667

668

669

670

671 (b) UHPM.

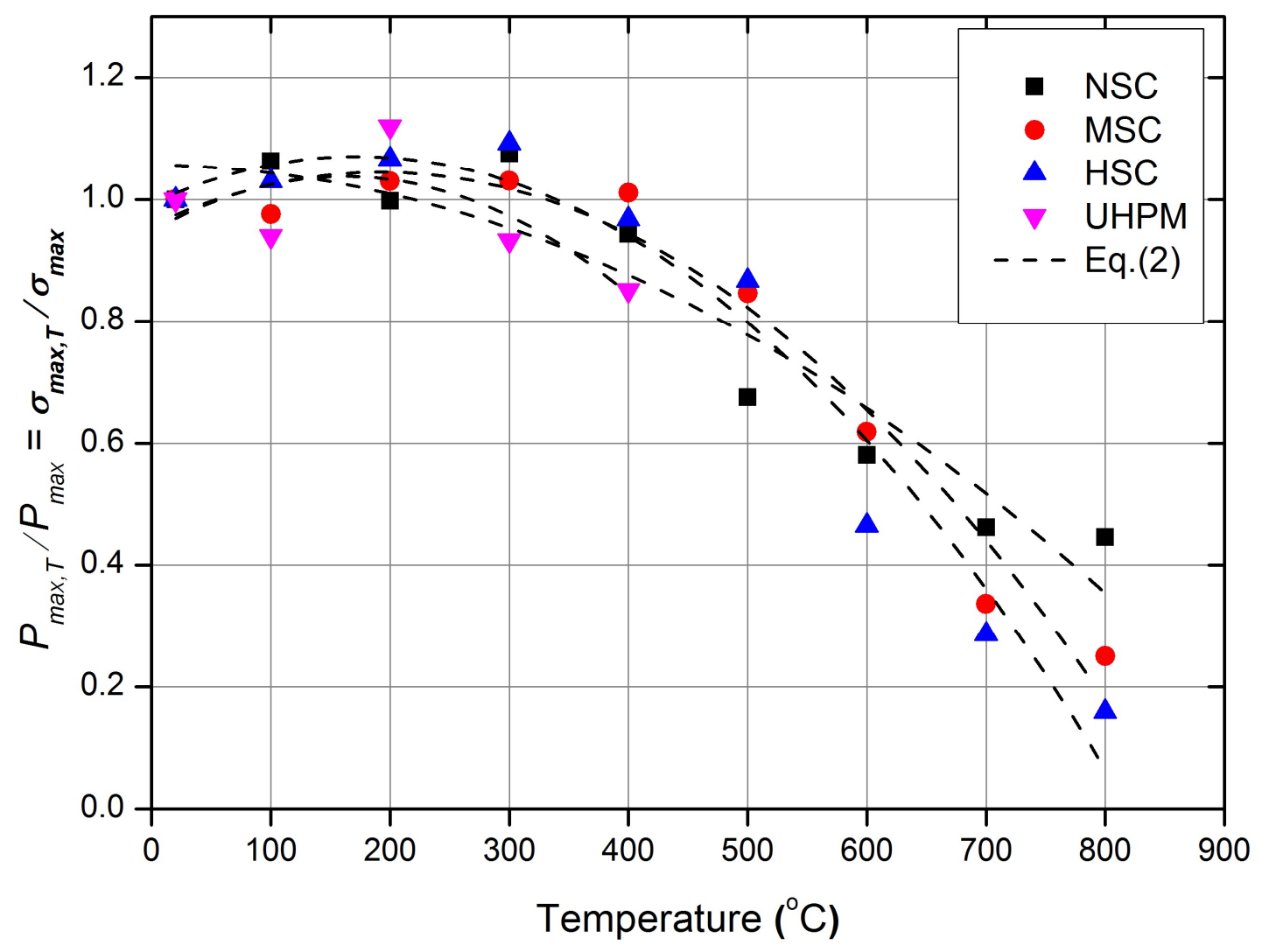

672 Fig. 11. Variation in maximum pull-out load and stress of 5DH fibre as a function of 673 temperature. 


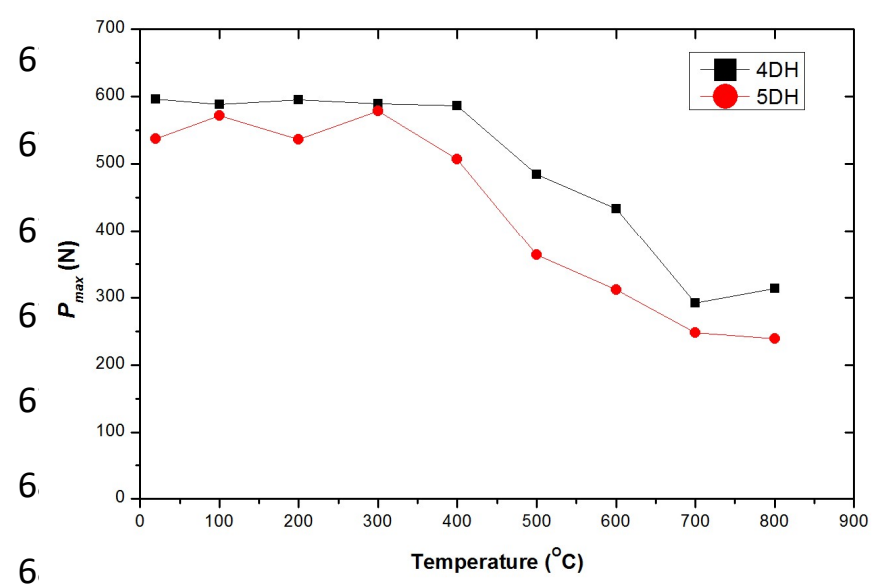

(a)

6

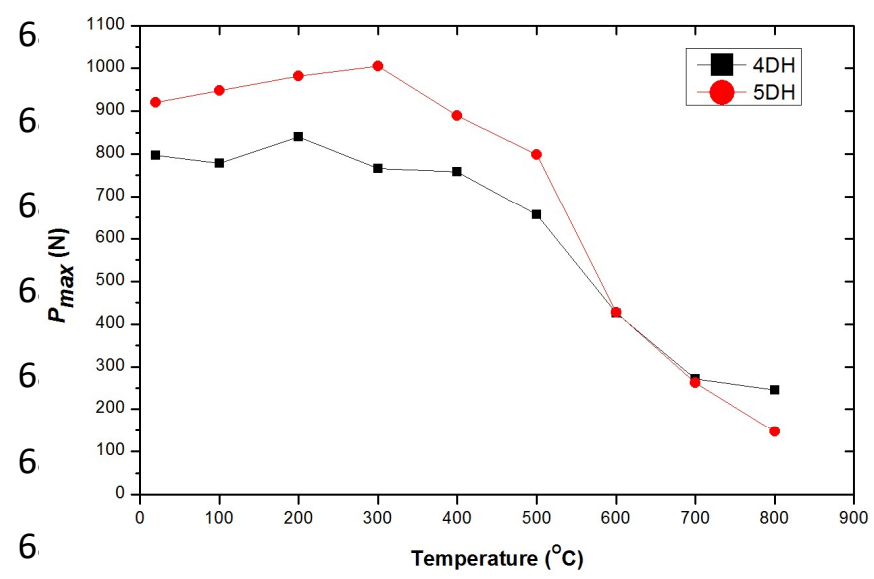

6

691

692

693

694

695

696

697

698

699

700

701

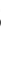

(c)

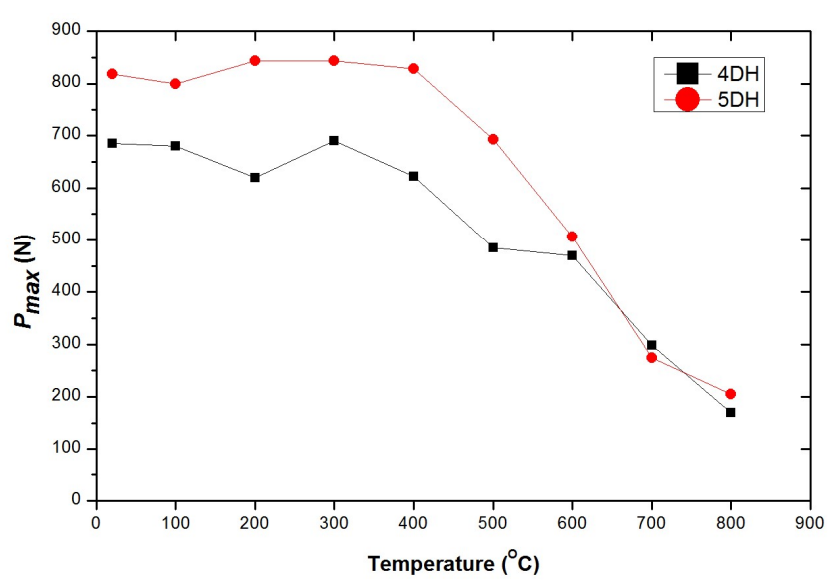

(b)

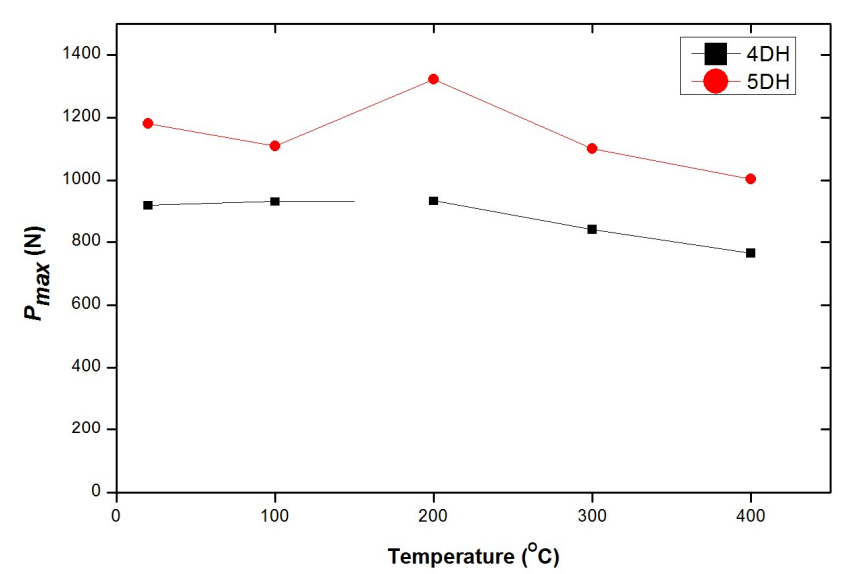

(d)

Fig. 12. Comparison in maximum pull-out load of both fibres at elevated temperatures. (a) NSC, (b) MSC, (c) HSC and (d) UHPM.

$$
\text { NSC, (b) MSC, (c) HSC and (d) UHPM. }
$$




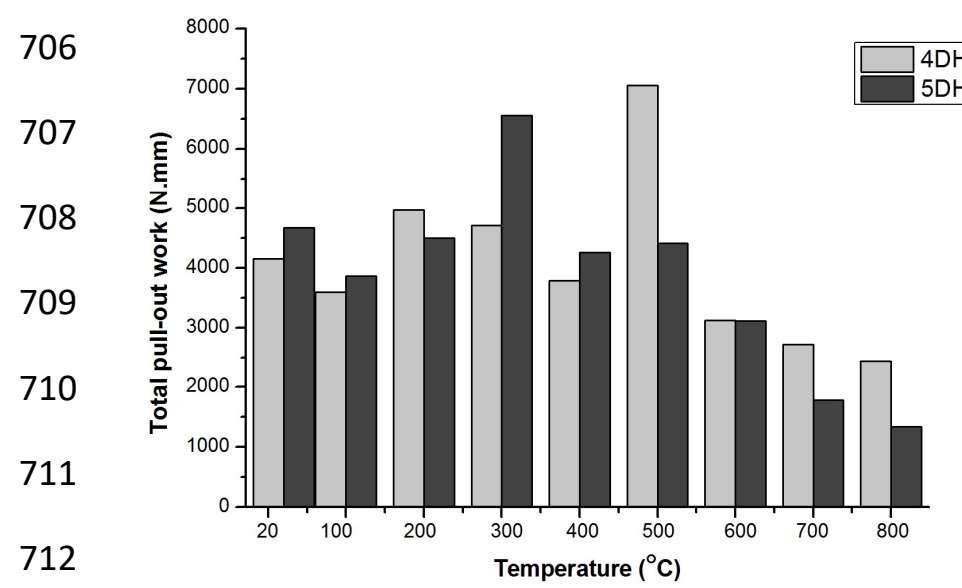

(a)

713

714

715

716

717

718

719

720

721

722

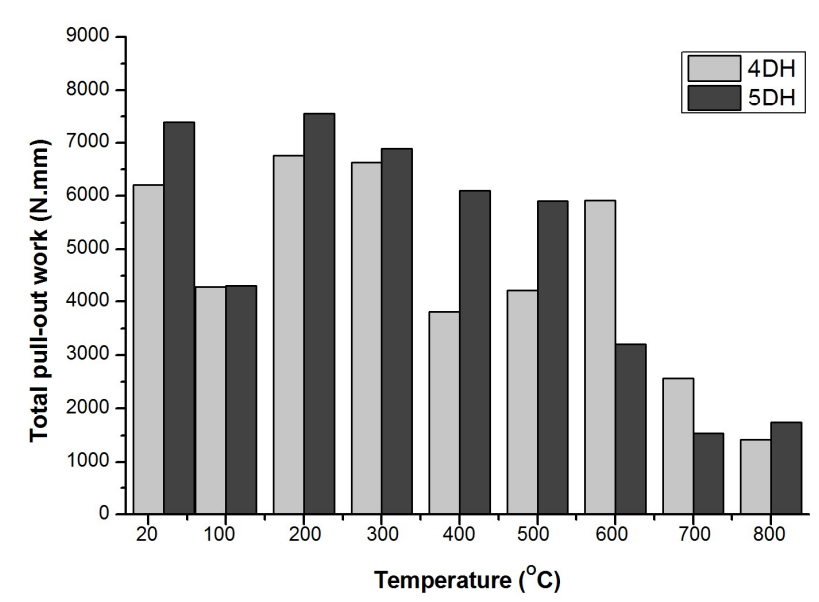

(c)

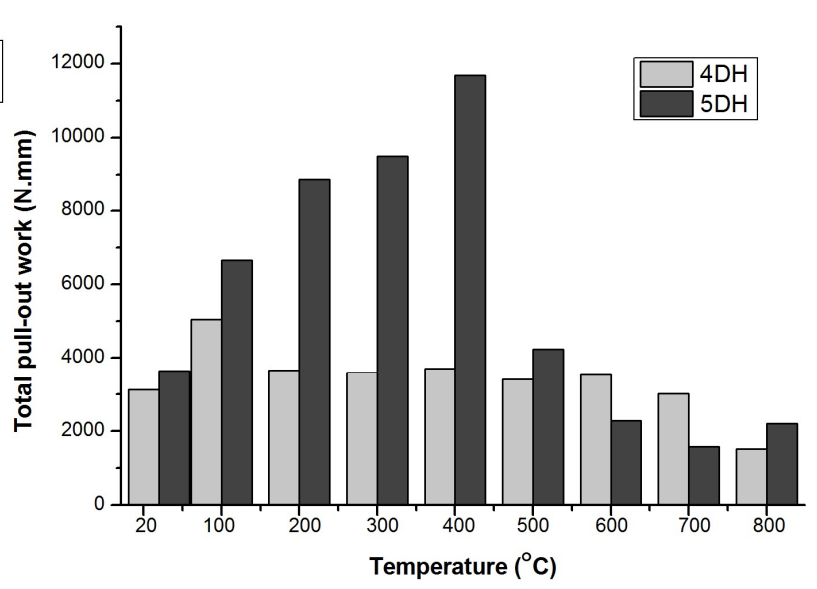

(b)

(d)

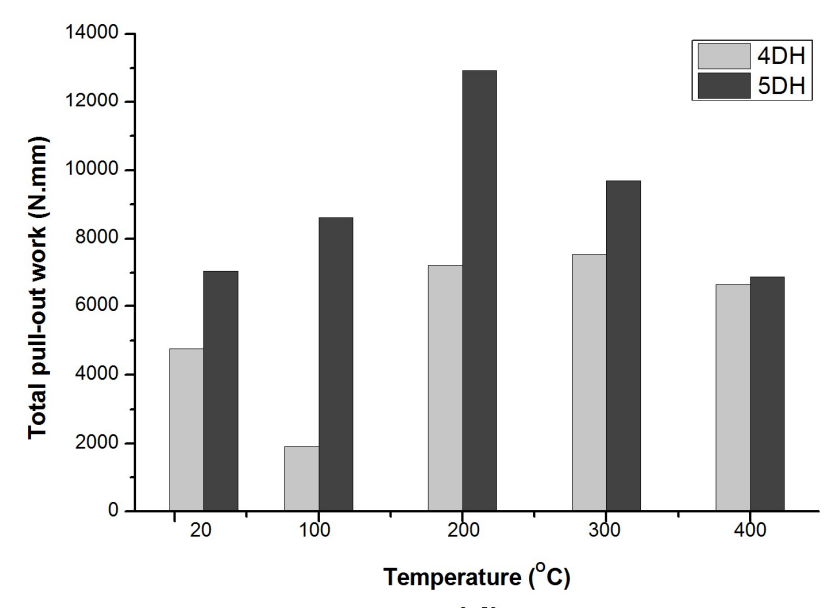

Fig. 13. Comparison in total pull-out work of both fibres at elevated temperatures. (a) NSC, (b) MSC, (c) HSC and (d) UHPM. 
Table 1

733 Mix design of mixtures

\begin{tabular}{|c|c|c|c|c|c|c|c|c|c|c|}
\hline \multirow[t]{3}{*}{$\begin{array}{l}\text { Matrix } \\
\text { type }\end{array}$} & \multirow{3}{*}{$\begin{array}{l}\text { Cement } \\
\left(\mathrm{kg} / \mathrm{m}^{3}\right)\end{array}$} & \multirow{3}{*}{$\begin{array}{l}\text { Silica } \\
\text { fume } \\
\left(\mathrm{kg} / \mathrm{m}^{3}\right)\end{array}$} & \multirow{3}{*}{$\begin{array}{c}\text { Fly } \\
\text { ash } \\
\left(\mathrm{kg} / \mathrm{m}^{3}\right)\end{array}$} & \multirow{3}{*}{$\begin{array}{l}\text { Quartz } \\
\left(\mathrm{kg} / \mathrm{m}^{3}\right)\end{array}$} & \multicolumn{3}{|c|}{$\begin{array}{l}\text { Aggregate } \\
\left(\mathrm{kg} / \mathrm{m}^{3}\right)\end{array}$} & \multirow{3}{*}{$\begin{array}{c}\text { Superplasticizer } \\
\left(\mathrm{kg} / \mathrm{m}^{3}\right)\end{array}$} & \multirow{3}{*}{$\begin{array}{l}\text { Water } \\
\left(\mathrm{kg} / \mathrm{m}^{3}\right)\end{array}$} & \multirow{3}{*}{$\begin{array}{l}\text { W/B } \\
(-)\end{array}$} \\
\hline & & & & & \multirow{2}{*}{$\begin{array}{l}\text { C.A } \\
6-8 \mathrm{~mm}\end{array}$} & \multicolumn{2}{|r|}{ F.A } & & & \\
\hline & & & & & & $\begin{array}{l}\text { C.G.S } \\
0-4 \mathrm{~mm}\end{array}$ & $\begin{array}{l}\text { F.G.S } \\
150-600 \mu \mathrm{m}\end{array}$ & & & \\
\hline NSC & $364^{\mathrm{a}}$ & - & - & - & 979 & 812 & - & - & 200 & 0.55 \\
\hline MSC & $350^{\mathrm{b}}$ & - & 107 & - & 660 & 1073 & - & - & 205 & 0.45 \\
\hline HSC & $480^{\mathrm{b}}$ & - & 45 & - & 850 & 886 & - & 6 & 210 & 0.40 \\
\hline UHPM & $710^{\mathrm{b}}$ & 230 & - & 210 & - & - & 1020 & 30.7 & 127 & 0.11 \\
\hline
\end{tabular}

734 a Portland-limestone cement CEM II 32,5R

735 b Portland cement CEM III $52.5 \mathrm{~N}$

736

737

738

Table 2

The measured geometric properties of hooked-end fibres

\begin{tabular}{ccccccccccccc}
\hline Fibre type & $f_{\text {uts }}(\mathrm{MPa})$ & $l_{f}(\mathrm{~mm})$ & $d_{f}(\mathrm{~mm})$ & \multicolumn{4}{c}{ Hook length $(\mathrm{mm})$} & \multicolumn{3}{c}{ Hook angles $\left({ }^{\circ}\right)$} & \multicolumn{2}{c}{ Hook height $(\mathrm{mm})$} \\
\cline { 5 - 12 } & & & & & $L_{1}$ & $L_{2}$ & $L_{3}$ & $L_{4}$ & $\alpha$ & $\beta$ & $H_{1}$ & $H_{2}$ \\
\hline 4D65/60 BG & 1500 & 60 & 0.90 & 2.98 & 2.62 & 3.05 & - & 35.1 & 33.8 & 4.37 & 2.20 \\
5D65/60 BG & 2300 & 60 & 0.90 & 2.57 & 2.38 & 2.57 & 2.56 & 27.9 & 30.5 & 2.96 & 1.57 \\
\hline
\end{tabular}

739

740

741

Table 3

742

The results of compressive strength at elevated temperatures $\left(20-800^{\circ} \mathrm{C}\right)$

\begin{tabular}{ccccc}
\hline Temperature & \multicolumn{4}{c}{ Compressive strength (MPa) } \\
$\left({ }^{\circ} \mathrm{C}\right)$ & NSC & MSC & HSC & UHPM \\
\cline { 2 - 5 } 20 & 33 & 54 & 71 & 148 \\
100 & 31 & 52 & 69 & 151 \\
200 & 32 & 57 & 72 & 152 \\
300 & 30 & 53 & 66 & 155 \\
400 & 29 & 50 & 64 & 140 \\
500 & 25 & 45 & 62 & - \\
600 & 18 & 35 & 42 & - \\
700 & 13 & 31 & 38 & - \\
800 & 11 & 23 & 34 & - \\
\hline
\end{tabular}

749

750

751

752

753 
Table 4

Pull-out tests results of $4 \mathrm{DH}$ fibres at elevated temperatures $\left(20-800^{\circ} \mathrm{C}\right)$

\begin{tabular}{|c|c|c|c|c|c|c|c|c|c|c|}
\hline Material & property & $20^{\circ} \mathrm{C}$ & $100^{\circ} \mathrm{C}$ & $200^{\circ} \mathrm{C}$ & $300^{\circ} \mathrm{C}$ & $400^{\circ} \mathrm{C}$ & $500^{\circ} \mathrm{C}$ & $600^{\circ} \mathrm{C}$ & $700^{\circ} \mathrm{C}$ & $800^{\circ} \mathrm{C}$ \\
\hline \multirow{4}{*}{ NSC } & $P_{\max }(\mathrm{N})$ & 596 & 588 & 595 & 589 & 586 & 484 & 433 & 313 & 292 \\
\hline & $\sigma_{f, \max }(\mathrm{MPa})$ & 937 & 925 & 936 & 926 & 922 & 761 & 681 & 492 & 459 \\
\hline & $S_{\max }(\mathrm{mm})$ & 2.58 & 1.45 & 3.25 & 2.03 & 1.59 & 2.10 & 1.73 & 11.04 & 14.33 \\
\hline & $W_{\text {total }}(\mathrm{N} \mathrm{mm})$ & 4154 & 3600 & 4968 & 4715 & 3789 & 7057 & 3127 & 2723 & 2445 \\
\hline \multirow{4}{*}{ MSC } & $P_{\max }(\mathrm{N})$ & 685 & 680 & 620 & 691 & 622 & 485 & 470 & 299 & 170 \\
\hline & $\sigma_{f, \max }(\mathrm{MPa})$ & 1077 & 1070 & 975 & 1087 & 978 & 763 & 739 & 470 & 267 \\
\hline & $S_{\max }(\mathrm{mm})$ & 1.68 & 1.43 & 1.30 & 1.48 & 1.22 & 2.44 & 1.05 & 4.45 & 2.32 \\
\hline & $W_{\text {total }}(\mathrm{N} \mathrm{mm})$ & 3123 & 5043 & 3661 & 3593 & 3707 & 3402 & 3531 & 3024 & 1525 \\
\hline \multirow{4}{*}{$\mathrm{HSC}$} & $P_{\max }(\mathrm{N})$ & 797 & 779 & 840 & 766 & 759 & 656 & 426 & 272 & 245 \\
\hline & $\sigma_{f, \max }(\mathrm{MPa})$ & 1254 & 1225 & 1321 & 1205 & 1194 & 1032 & 670 & 428 & 385 \\
\hline & $S_{\max }(\mathrm{mm})$ & 1.76 & 1.11 & 1.57 & 1.53 & 1.16 & 2.12 & 2.24 & 4.91 & 3.44 \\
\hline & $W_{\text {total }}(\mathrm{N} \mathrm{mm})$ & 6210 & 4271 & 6756 & 6627 & 3809 & 4210 & 5917 & 2563 & 1419 \\
\hline \multirow{4}{*}{ UHPM } & $P_{\max }(\mathrm{N})$ & 918 & 931 & 933 & 840 & 766 & 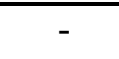 & 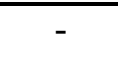 & - & 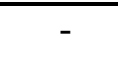 \\
\hline & $\sigma_{f, \max }(\mathrm{MPa})$ & 1444 & 1465 & 1468 & 1321 & 1205 & - & - & - & - \\
\hline & $S_{\max }(\mathrm{mm})$ & 1.55 & 1.42 & 1.57 & 1.58 & 1.59 & - & - & - & - \\
\hline & $W_{\text {total }}(\mathrm{N} \mathrm{mm})$ & 4763 & 1922 & 7222 & 7540 & 6627 & - & - & - & - \\
\hline
\end{tabular}

757

Table 5

759

\begin{tabular}{|c|c|c|c|c|c|c|c|c|c|c|}
\hline Material & property & $20^{\circ} \mathrm{C}$ & $100^{\circ} \mathrm{C}$ & $200^{\circ} \mathrm{C}$ & $300^{\circ} \mathrm{C}$ & $400^{\circ} \mathrm{C}$ & $500^{\circ} \mathrm{C}$ & $600^{\circ} \mathrm{C}$ & $700^{\circ} \mathrm{C}$ & $800^{\circ} \mathrm{C}$ \\
\hline \multirow{4}{*}{ NSC } & $P_{\max }(\mathrm{N})$ & 537 & 571 & 536 & 578 & 507 & 363 & 312 & 248 & 239 \\
\hline & $\sigma_{f, \max }(\mathrm{MPa})$ & 845 & 898 & 843 & 909 & 797 & 571 & 491 & 390 & 376 \\
\hline & $S_{\max }(\mathrm{mm})$ & 2.33 & 1.78 & 2.11 & 1.35 & 1.32 & 2.66 & 1.30 & 1.54 & 1.94 \\
\hline & $W_{\text {total }}(\mathrm{N} \mathrm{mm})$ & 4671 & 3862 & 4502 & 6553 & 4259 & 4417 & 3117 & 1781 & 1336 \\
\hline \multirow{4}{*}{ MSC } & $P_{\max }(\mathrm{N})$ & 819 & 799 & 843 & 844 & 828 & 693 & 507 & 275 & 205 \\
\hline & $\sigma_{f \max }(\mathrm{MPa})$ & 1288 & 1257 & 1326 & 1327 & 1302 & 1090 & 797 & 433 & 322 \\
\hline & $S_{\max }(\mathrm{mm})$ & 2.25 & 1.61 & 1.75 & 1.19 & 2.04 & 1.51 & 1.32 & 2.25 & 1.20 \\
\hline & $W_{\text {total }}(\mathrm{N} \mathrm{mm})$ & 3645 & 6659 & 8874 & 9506 & 11679 & 4228 & 2287 & 1574 & 2211 \\
\hline \multirow{4}{*}{ HSC } & $P_{\max }(\mathrm{N})$ & 920 & 948 & 981 & 1005 & 890 & 798 & 427 & 263 & 147 \\
\hline & $\sigma_{f, \max }(\mathrm{MPa})$ & 1447 & 1491 & 1543 & 1581 & 1400 & 1255 & 672 & 414 & 231 \\
\hline & $S_{\max }(\mathrm{mm})$ & 1.83 & 1.66 & 0.98 & 1.93 & 1.89 & 1.53 & 2.46 & 1.46 & 1.51 \\
\hline & $W_{\text {total }}(\mathrm{N} \mathrm{mm})$ & 7384 & 4298 & 7547 & 6884 & 6098 & 5902 & 3199 & 1542 & 1742 \\
\hline \multirow{4}{*}{ UHPM } & $P_{\max }(\mathrm{N})$ & 1181 & 1110 & 1323 & 1102 & 1005 & - & - & - & - \\
\hline & $\sigma_{f, \max }(\mathrm{MPa})$ & 1858 & 1746 & 2081 & 1733 & 1581 & - & - & - & - \\
\hline & $S_{\max }(\mathrm{mm})$ & 1.75 & 1.38 & 2.29 & 1.84 & 1.93 & - & - & - & - \\
\hline & $W_{\text {total }}(\mathrm{N} \mathrm{mm})$ & 7043 & 8610 & 12937 & 9694 & 6883 & - & - & - & - \\
\hline
\end{tabular}

761

762

763

764 
766

767

768

769

770

771

772

773

774

775

776

777 